\title{
WestVirginiaUniversity
}

THE RESEARCH REPOSITORY @ WVU

Graduate Theses, Dissertations, and Problem Reports

2014

\section{Creation of in vitro disease models using micro-nanoengineering}

\author{
Allison Bruce
}

Follow this and additional works at: https://researchrepository.wvu.edu/etd

\section{Recommended Citation}

Bruce, Allison, "Creation of in vitro disease models using micro-nanoengineering" (2014). Graduate Theses, Dissertations, and Problem Reports. 7303.

https://researchrepository.wvu.edu/etd/7303

This Thesis is protected by copyright and/or related rights. It has been brought to you by the The Research Repository @ WVU with permission from the rights-holder(s). You are free to use this Thesis in any way that is permitted by the copyright and related rights legislation that applies to your use. For other uses you must obtain permission from the rights-holder(s) directly, unless additional rights are indicated by a Creative Commons license in the record and/ or on the work itself. This Thesis has been accepted for inclusion in WVU Graduate Theses, Dissertations, and Problem Reports collection by an authorized administrator of The Research Repository @ WVU. For more information, please contact researchrepository@mail.wvu.edu. 


\title{
Creation of in vitro Disease Models Using Micro-/Nanoengineering
}

\author{
by
}

\begin{abstract}
Allison Bruce
Thes is Submitted to the

Benjamin M. Statler College of Engine ering and Mine ral Resources at West Virginia University

in partial fulfillment of the requirements for the degree of

Master of Scie nce in Engine ering
\end{abstract}

Yong Yang, Ph.D., Chair

Cerase la-Zoica Dinu, Ph.D.

Charter D. Stinespring, Ph.D.

Morgantown, West Virginia

2014

Copyright 2014 Allis on Bruce 


\begin{abstract}
All rights reserved
INFORMATION TO ALL USERS

The quality of this reproduction is dependent upon the quality of the copy submitted.

In the unlikely event that the author did not send a complete manuscript and there are missing pages, these will be noted. Also, if material had to be removed,

a note will indicate the deletion.
\end{abstract}

UMI 1555062

Published by ProQuest LLC (2014). Copyright in the Dissertation held by the Author.

Microform Edition (c) ProQuest LLC.

All rights reserved. This work is protected against

unauthorized copying under Title 17, United States Code

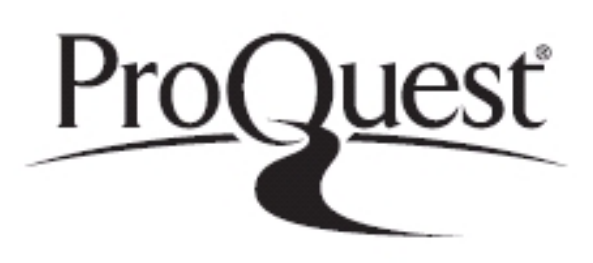

ProQuest LLC.

789 East Eisenhower Parkway

P.O. Box 1346

Ann Arbor, Ml $48106-1346$ 


\title{
Abstract \\ Creation of in vitro Disease Models Using Micro-/Nanoengineering
}

\begin{abstract}
Allison Bruce
Cells are typically housed in a complex microenvironment (ECM) in vivo, where the cells interact with the extracellular matrix (ECM) and neighboring cells. The ECM provides physical support for cells and affects cell adhesion, migration, proliferation, differentiation, and gene expression. Primary components of the ECM include fibrous proteins which contribute significant nanotopography cues to cells. Due to limitations of two-dimensional (2-D) in vitro studies where cells are cultured on flat, plastic substrates, the conventional cell culture does not mimic the in vivo scenario. This manifests the critical need for biomimetic cell culture platforms which mimic the in vivo microenvironment. During my graduate studies, two in vitro disease models were constructed to investigate cell-substrate and cell-cell interactions.

In Chapter I, nanotopographical effects on cell responses were examined. Focal adhesions and nuclear deformation of normal human lung fibroblasts (NHLFs) were investigated. In general, nanoscale gratings hindered cell spreading and thus reduced cell size while increasing the nuclear volume. On the other hand, nanoscale pillars, depending on the feature size and spacing, might modulate the focal adhesions and nuclear size towards opposite directions. Our observations suggested that it was focal adhesion area instead of focal adhesion size that affected nuclear deformation. Therefore, nanotopography could be optimized to modulate cell adhesion and nuclear volume, which would provide a useful tool to regulate cell phenotypes and functions for end applications.

In Chapter II, the effects of cell-cell and cell-matrix interactions on tumor cell survival within an engineered bone marrow microenvironment for Acute Lymphoblastic Leukemia (ALL) were evaluated. In this study, biologically relevant populations of primary human derived bone marrow stromal cells (BMSCs), osteoblasts and a human ALL cell line representative of an aggressive phenotype were used. Traditional 2-D co-culture, 3-D static culture in collagen, and 3-D cultures with flow were evaluated to determine response to a commonly used chemotherapeutic agent, Ara-C. 3-D co-culture models showed higher survival of tumor cells during Ara-C exposure as well as enhanced protection during chemotherapy stress conferred by microenvironment cells.
\end{abstract}




\section{Acknowledge ments}

I would like to thank my advisor, Dr. Yong Yang, for his patience, advice, and guidance on any issues that have come up during my time as his student. He has provided me with the knowledge, vision, motivation, and confidence for my not only my Master's study and research, but also for the future.

I would also like to thank my committee members, Dr. Cerasela-Zoica Dinu and Dr. Charter Stinespring, for their continuous encouragement, help, and input.

I would like to thank all the graduate students that have helped and influenced me along the way. Xiaoyan Yu for her contributions to the nanotopography work and supportive conversations related to various projects. Ryan Mezan for his computer expertise and help with imaging analysis. Also, I would like to extend enormous gratitude to Dr. Laura Gibson, as well as, Rebecca Evans for their encouragement, support, and insight on the three-dimensional co-culture project. I would also like to thank former Bionano Shared Research Facility Manager, Siera Talbott, for her countless invaluable conversations, training, and help.

My family has supported me in every step of this journey and I could not thank them enough for all that they have done. My parents and sister are true role models and have always been there to help me through anything. Their hard work and ability to overcome obstacles has provided the drive necessary to complete this goal. 


\section{Table of Contents}

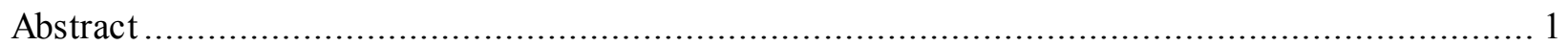

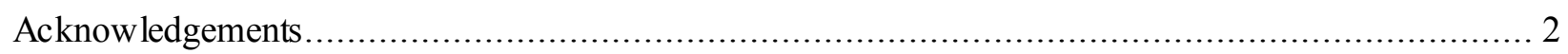

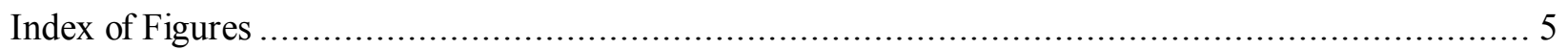

I. Nanotopography Modulated Nuclear Deformation and Focal Adhesions ...................................... 7

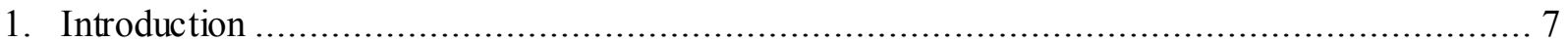

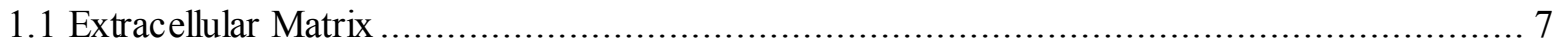

1.2 Nanotopographical Effects on Cellu lar Responses .......................................................... 7

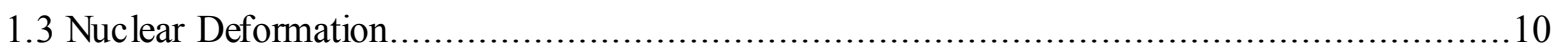

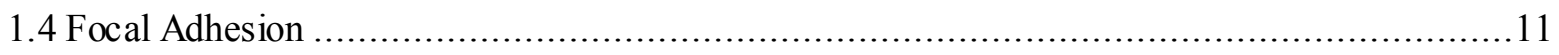

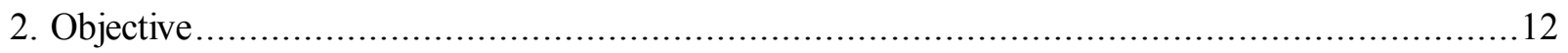

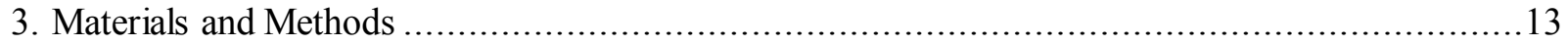

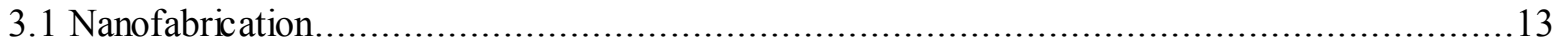

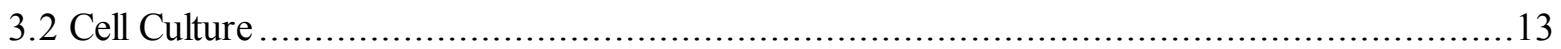

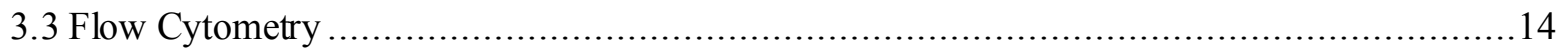

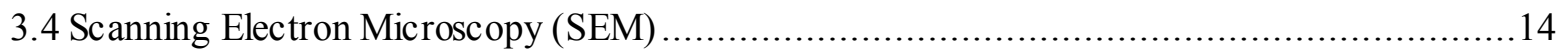

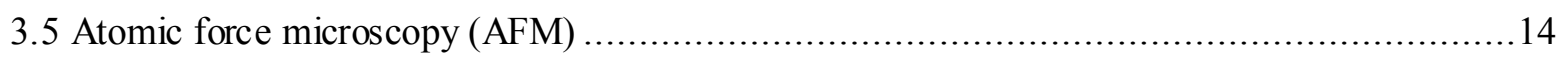

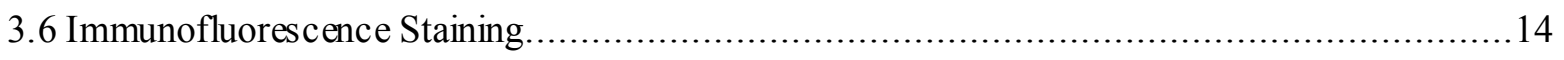

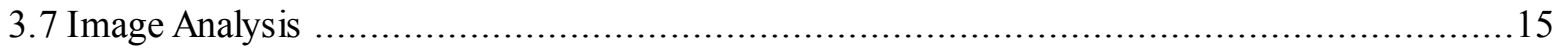

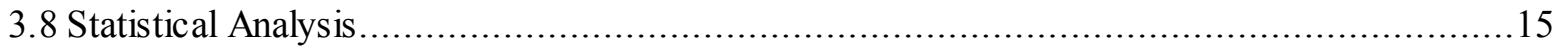

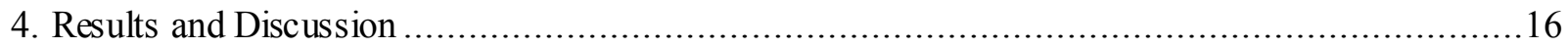

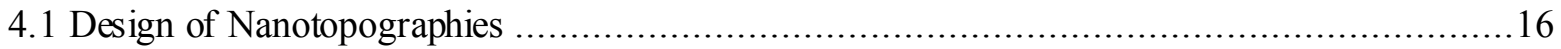

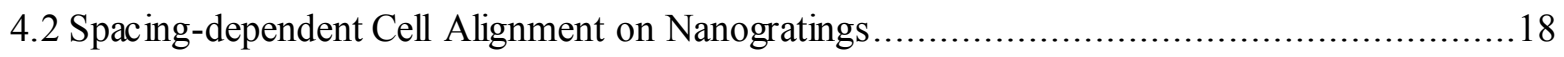

4.3 Nanogratings Modulated Focal Adhesions and Nuclear Size …......................................21

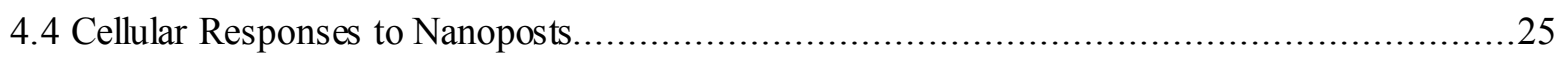

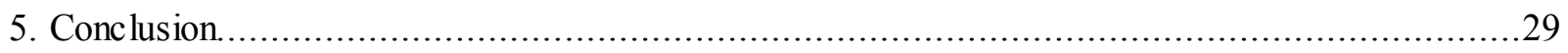

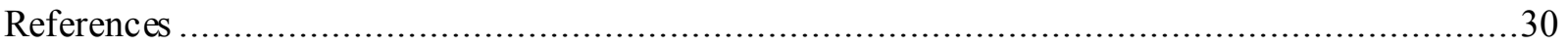

II. Three-dimensional Microfluidic Co-Culture Model of the Bone Marrow Mic roenvironment for the

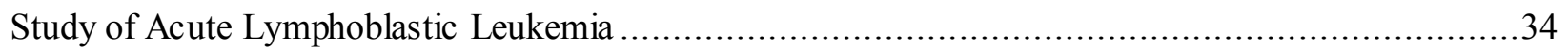

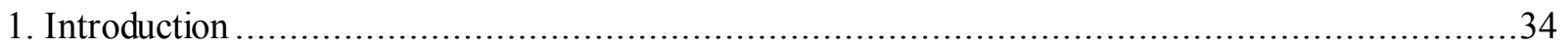

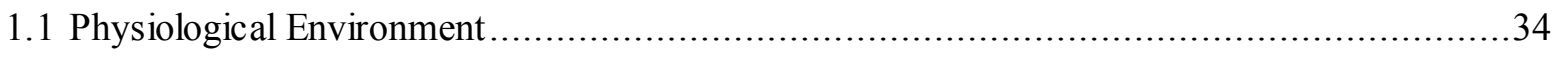

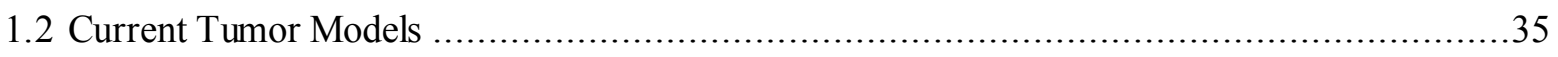

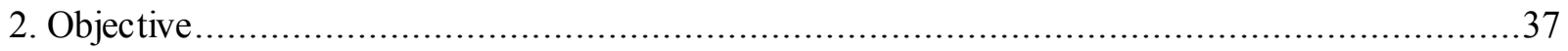




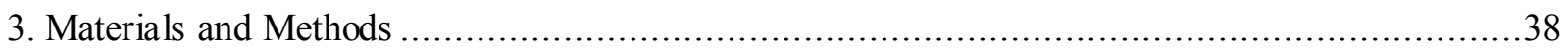

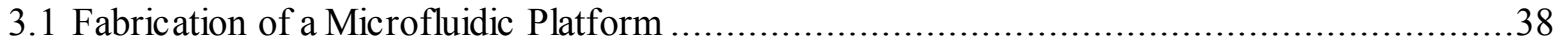

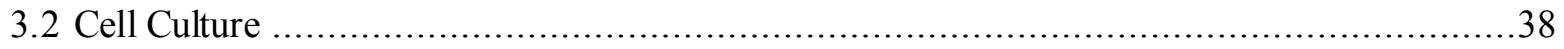

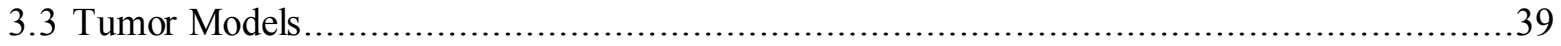

3.4 Chemotherapeutic Reagents and Treatment....................................................40

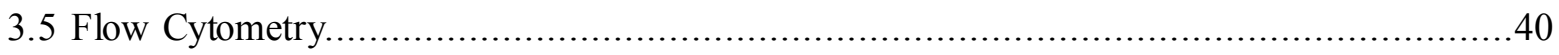

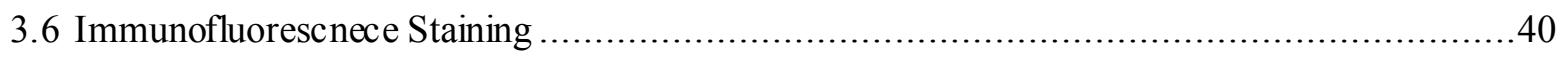

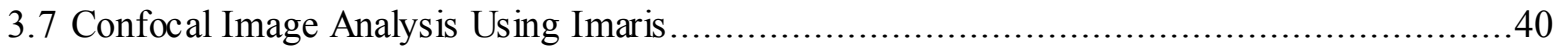

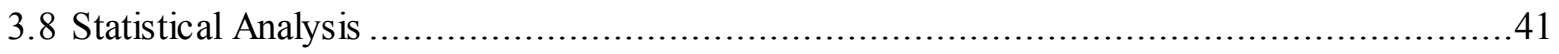

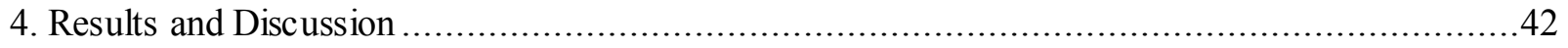

4.1 Essential Elements in Tumor Models ............................................................42

4.2 Microfluidic Design and Fabrication ..............................................................43

4.3 Co-Culture Models...................................................................................... 44

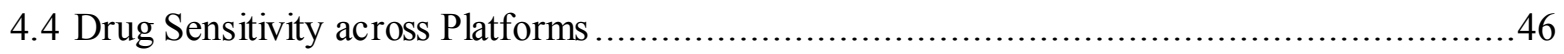

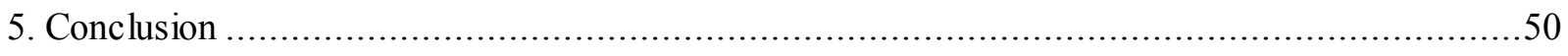

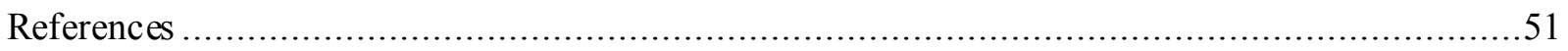




\section{Index of Figures}

Figure 1.1: (A) SEM micrographs of nanotogratings, (B) nanoposts, and (C) AFM images of typical nanotopographies. Two-dimensional profile indic ated the feature height.

Figure 1.2: Nanotopography-dependent cell spreading. The nuclei were stained with DAPI in blue, the actin filaments were stained with phalloidin in green, and focal adhesions were stained with paxillin in red.

Figure 1.3: Cell spreading on nanogratings. A) Confocal and B) SEM images of NHLFs grown on nanogratings. The yellow arrows point to the nanograting direction. Scale bars $=1 \mu \mathrm{m}$. .20

Figure 1.4: Image analysis using Imaris. The confocal images of focal adhesion protein paxillin structures on (A) nanogratings were extracted using Imaris after applying threshold and shown in (B)

Figure 1.5: Nanogratings-modulated focal adhesion size. The straight horizontal line indicated the average focal adhesion size of NHLFs on the flat control.

Figure 1.6: Typical projected nuclear area and reconstructed nuclear volume of cells on nanogratings ...23

Figure 1.7: Nuclear deformation on nanotopographies. (A) Nuclear area and (B) nuclear volume comparison of cells grown on nanogratings. The straight horizontal lines indicated the average nuclear area and volume of NHLFs on the flat control.

Figure 1.8: SEM micrographs of human fibroblasts grown on (A) nanopillars 300-1.9X and (B) nanopillars 1000-1.9X. The boxed regions were enlarged to show the filopodia extension...

Figure 1.9: Image analysis using Imaris. The confocal images of focal adhesion protein paxillin structures on (A) nanogratings were extracted using Imaris after applying threshold and shown in (B). .26

Figure 1.10: Nanopillars-modulated average focal adhesion size. .26

Figure 1.11: Nanopillar modulated deformation of (A) nuclear area and (B) nuclear volume of fibroblasts....

Figure 2.1: Schematic illustration of tumor models. The three factors tested in this study include dimensionality, cell-cell interactions and interstitial flow....

Figure 2.2: A typical 3-D microfluidic co-culture model. (A) The microfluidic platform consists of 4 microchannels, each $500 \mu \mathrm{m}$ in width, $75 \mu \mathrm{m}$ in height and $2 \mathrm{~cm}$ in length. The divergent angles are $30^{\circ}$. Near the inlets and outlet there are perfusion channels. The enlarged boxed area illustrates multiple cell types embedded in a 3-D matrix. (B) Optical image of the microfluidic platform. (C) SEM images of top view (upper panel) and side view (lower panel) of the perfusion channels .43 
Figure 2.3: Representative tumor models. (A) Confocal and Imaris reconstruction images of the tumor models at low magnific ation (20X), high magnification (40X) and high magnification cross sections (CS). The cell-cell interactions in z-direction in the boxed region of CS images are enlarged in Row 4. The heights for 2-D and 3D CS images are $10 \mu \mathrm{m}$ and $30 \mu \mathrm{m}$, respectively. (B) 3-D reconstruction images rotated via $\mathrm{x}$ - and $\mathrm{y}$-axis revealing cell-cell interactions. .45

Figure 2.4: Viability analysis using Annexin V. (A) Typical flow cytometry analysis for untreated 2-D tumor model (left) and Ara-C treated 3-D co-culture model (right) using collagenase to digest collagen matrix. (B) Typical immunofluorescence image analysis of untreated (left) and treated (right) 3-D

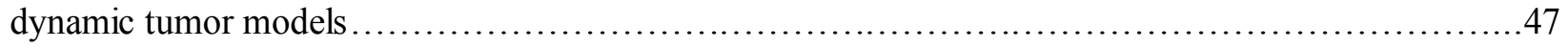

Figure 2.5: Comparison in chemoresistance of tumor cells to Ara-C among a variety of tumor models. (A) The effects of dimensionality, co-culture and interstitial flow on the viability of tumor cells. Bracket show s signific ant $(\mathrm{p}<0.1)$ difference betw een treated tumor and treated co-culture.

Figure 2.6. The effects of 3-D culture on tumor cell viability under the co-culture condition. Brackets reveal significant $(\mathrm{p}<0.05)$ difference in 3-D and 2-D models. All 3-D models showed significant

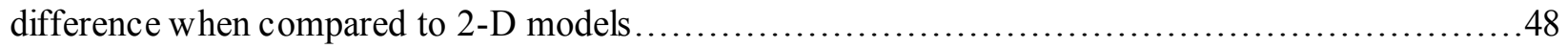




\section{Nanotopography Modulated Nuclear Deformation and Focal Adhesions}

\section{Introduction}

\subsection{Extracellular Matrix}

Regenerative medicine, aiming at the repair or replacement of cells, tissues and organs [1], holds great promise for the treatment of diseases that are untreatable at present, such as various gene and neurological disorders, cardiovascular diseases, as well as hematological malignancies. Realization of this potential remains limited by current challenges associated with the control of cell phenotypes and functions in cell culture [2]. In this respect, the fate of cells is dictated by the in vivo microenvironment where these cells interact with both the extracellular matrix (ECM) as well as with neighboring cells. The ECM serves as a structural support for cells and provides, in concert with the spatio-temporally arranged signaling molecules and external stimuli, topographical and mechanical cues for cell adhesion, spreading, migration, proliferation and differentiation.

The ECM is composed of diverse biomacromolecules including glycosaminoglycans, fibrous proteins such as collagen, elastin, and fibronectin, and nonfibrous proteins such as grow th factors and cytokines, with size ranging from several to hundreds of nanometers [3]. The ECM constructed from these biomacromolecules often includes significant topography at the nanoscale level. For example, basement membranes, which are a ubiquitous component of ECM that plays an important role in tissue development and organization, manifest a complex three-dimensional (3-D) texture with sizes in the nanometer range [4-9].

\subsection{Nanotopographical Effects on Cellular Responses}

A number of recent findings strongly support that cell responses are highly sensitive to topographical cues on a synthetic surface, in particular, at the nanoscale level [10-13]. In addition to inducing pronounced changes to cell morphology, migration, and proliferation, topographical cues could potentially help induce the differentiation of stem cells into certain lineages such as neuron $[11,14,15]$, muscle [16], and bone $[12,13]$. 
Cellular responses to external cues begin with formation of focal adhesions via binding and clustering of integrins onto the adhesive ligands present in the substrate. Formation of focal adhesions and actin stress fibers control the adhesion and spreading of cells. As a dynamic process, focal adhesions are constantly assembling and disassembling to enable motility and cellular migration [17]. The shape, size, spacing and depth of nanoscale features have profound influence on cell morphology, spreading and migration. The use of nanotopography can dramatically enlarge the surface area, thus enhanc ing cell adhesion and proliferation [18,19]; however, the apparent surface that cells can 'sense' is determined by the dimensions and geometry (e.g., gratings, pillars, and pits) of nanotopography relative to cell dimensions $[12,13,20,21]$. For instance, human fibroblasts responded differently to demixed isotropic nanoislands of 13, 35 and $95 \mathrm{~nm}$ in height. Fibroblasts displayed highly spread morphology containing well-defined cytoskeleton on the 13-nm islands, but had deformed cell spreading with diffuse actin and less stress fibers when the height of the islands increased [22,23]. Human endothelial cell also showed a highly spread cell morphology on the 13-nm islands [22]. How ever, on the 95-nm islands, different from fibroblasts, endothelial cells appeared to have larger lamellae, the edges of which appeared to be anchored to the nanoislands and had increased numbers of stress fibers [24].

Anisotropic nanotopography could guide cells to spread and migrate preferentially. Teixeira et al. studied human corneal epithelial cells on silicon ( $\mathrm{Si}$ ) nanogratings with a linewidth ranging from 70 to $1900 \mathrm{~nm}$, with a corresponding pitch of 400 to $4000 \mathrm{~nm}$ and two depths of $150 \mathrm{~nm}$ and $600 \mathrm{~nm}$. The cells cultured on the smooth control formed focal adhesions and stress fibers with no preferred orientations. On the nanogratings focal adhesions and stress fibers aligned along the nanogratings direction. The focal adhesion widths on any of the nanogratings were smaller than those on the smooth control. The size of focal adhesions increased with the ridge width up to $400 \mathrm{~nm}$ and remained constant when the ridge width was beyond $650 \mathrm{~nm}$. On all 600-nm deep grooves, cells aligned along the gratings had higher elongations than cells on the smooth control. Cell alignment resulted from anisotropic cell spreading, as the cells extended and retracted lamellipodia preferentially along the direction of the patterns. They observed that 
the average cell areas on all nanogratings were lower than those on the smooth control [20]. The alignment induced by nanotopography might be reduced with an increase in grating width. Up to $90 \%$ of the smooth muscle cells (SMCs) would align with nanogratings (350 $\mathrm{nm}$ and $500 \mathrm{~nm}$ in width) but only $37 \%$ of the cells would do so when cultured on $10 \mu \mathrm{m}$ wide ratings. Greatest alignment was observed on gratings of $800 \mathrm{~nm}$ height, and decreased as the height goes down to $300 \mathrm{~nm}$ [25]. Nuclear alignment and deformation could also be affected by the anisotropic nanotopography. On polydimethylsiloxane (PDMS) nanogratings (350 $\mathrm{nm}$ in width, $700 \mathrm{~nm}$ in pitch and $280 \mathrm{~nm}$ in depth), $62.0 \%$ of nuclei of human mesenchymal stem cells (hMSCs) oriented in a $15^{\circ}$ alignment angle compared to a random orientation of the nuclei on the flat control. The nanogratings elongated the nuclei to an elongation aspect ratio (nuclear long axis/short axis) range of 1-5 compared with the range of 1-3 on the flat control. The nanogratings also significantly decreased the average nuclear area to $145.1 \pm 4.1 \mu \mathrm{m}^{2}$ on nanogratings from $194.8 \pm 4.8$ $\mu \mathrm{m}^{2}$ on the flat control [26].

When the topography reduces the apparent surface area on which cells can sense, the topography restricts the focal adhesions, weakens cellular adhesion, and thus facilitates cell migration [27]. On 350nm gratings hMSCs exhibited a much smaller size of focal adhesion protein zyxin, $3.2 \pm 0.26 \mu \mathrm{m}^{2}$, compared to $5.3 \pm 0.55 \mu \mathrm{m}^{2}$ in the cells on planar controls. Fluorescence recovery after photobleaching (FRAP) measurements indicated that the turnover of GFP-zyxin proteins was increased on 350-nm gratings. Since the association of zyxin with focal adhesions was force-dependent, smaller zyxin-positive adhesion as well as its higher turnover rate suggested that the traction force in focal adhesions on $350-\mathrm{nm}$ gratings was decreased. These changes led to faster and more directional migration on 350-nm gratings, $15.6 \mu \mathrm{m} / \mathrm{h}$, compared with $8.3 \mu \mathrm{m} / \mathrm{h}$ observed on planar controls [28].

There is a general notion that proliferation increases with cell spreading. Nanotopography, very often, reduces the surface area cells can sense. Hence, a decrease in proliferation has been observed in cells cultured on nanogratings although the cell alignment, elongation and migration are enhanced [11,24,2933]. For instance, on PDMS nanogratings (350 nm in width, $700 \mathrm{~nm}$ in pitch, and $350 \mathrm{~nm}$ in depth) 
cytoskeleton and nuclei of hMSCs aligned and elongated along the nanogratings. The proliferation of hMSCs on the nanogratings was signific antly lower, $26.9 \pm 3.1 \%$ of BrdU incorporation compared to 35.7 $\pm 7.6 \%$ on flat surfaces [11]. Moveover, Dalby et al. have shown that the near-square nanopits stimulated hMSCs to produce bone mineral in vitro, in the absence of osteogenic supplements at levels similar to the cells cultured with osteogenic media [12]; while highly ordered nanopits permitted prolonged retention of multipotency of hMSCs [34].

\subsection{Nuclear Deformation}

External cues from cellular microenvironment may initiate cell adhesion, and can be transduced through cytoskeletal filaments and nuclear scaffolds to nucleus, ultimately influencing cell fate and functions [35]. In response to the external cues, the molecular connections between cell adhesion, cytoskeletal filaments and nuclear scaffolds may produce integrated changes in cell and nuclear structure [36]. Cell morphology and cytoskeleton organization influence cells via actin stress fibers [37-39]. Alteration in the actin-mediated tension affects cell spreading, contraction, and migration, thus modulating nuclear shape and plasticity. For instance, the differentiation of stem cells into a chondrocytic phenotype required a rounded cell shape. Direct comparison of cell and nuclear shape of hMSCs indicated that a more rounded nuclear shape was associated with the greatest expression of molecular markers associated with chondrogenesis [40]. Nuclear deformation can lead to conformational adaptation in chromatin structure and organization, which in turn affects transcriptional regulation [41] and then gene expression and protein synthesis $[35,42,43]$, eventually leading to the changes in proliferation, differentiation, or cell death $[44,45]$. Nuclear deformation strongly depends on the spatial organization and orientation of the actin cytoskeleton. The transmission of mechanical cues from the cytoskeleton to the nucleus may not only depend on cytoskeletal tension, but also on the orientation of the cytoskeletal filaments and the way the filaments are connected to the nucleus [46]. In particular, nuclear volume regulation has been identified as a key mechanism by which cell shape controls the expression of different genes, including those that control the cell cycle [46]. 


\subsection{Focal Adhesion}

Nanotopography can rearrange focal adhesion distribution and cytoskeleton assembly, which regulates cell and nuclear shape and polarization. The spatial confinement of focal adhesions, ultimately modulation of cell and nuclear shape, are crucial in the context of mechanotransduction [47]. It has been reported recently that the nuclear volume of human corneal epithelial cells grown on nanogratings increased as the pitch of the nanogratings increased from $400 \mathrm{~nm}$ to $2000 \mathrm{~nm}$ and there was a significant decrease in the cell modulus at $400 \mathrm{~nm}$ compared to the moduli for flat surfaces and for larger pitches of these chemically identical substrates [48]. 


\section{Objective}

The objective of this project was to examine nanotopographical effects on cell responses. In order to investigate nanotopography effects on cells, isotropic nanopillars and anistropic nanogratings were designed with dimensions above and below the accepted threshold of $500 \mathrm{~nm}$ with varying spacing. Human lung fibroblasts were cultured on this platform and focal adhesions and nuclear deformation were analyzed. Using this model, we planned to correlate focal adhesion size to nuclear deformation to establish optimal topography, thus, providing a tool to regulate cells by modulation of cell adhesions and nuclear volume. 


\section{Materials and Methods}

3.1 Nanofabrication

Nanotopographies including gratings and posts were written in a poly(methylmethacrylate) (PMMA)

thin film that was spin-coated onto a Si substrate using electron beam lithography (EBL).

A mixture of polydimethylsiloxane (PDMS) resin and curing agent (Sylgard 184 kit, Dow Corning, MI, USA) in a 10:1.05 w/w ratio was poured onto the EBL mold. After curing for $2 \mathrm{hr}$ at $70^{\circ} \mathrm{C}$, the inverse PDMS mold was peeled from the EBL mold.

Multiple PDMS molds were stitched to generate a large area of nanopatterned surface as a substrate so that enough cells could be seeded for subsequent biological analyses as reported previously[39]. Briefly, these PDMS molds with the nanopattern face-down were aligned on a Si wafer. A PDMS prepolymer layer spin-coated on a glass plate was pressed onto the unpatterned side of PDMS molds. The assembly was inverted, placed on a hot plate, and cured at $80^{\circ} \mathrm{C}$ for $2 \mathrm{hr}$. The multiple PDMS molds were stitched into a single mold. The stitched mold was then hot-embossed into polystyrene (PS) substrates, which served as a master mold to replicate PDMS working substrates. The PDMS substrates nanotopographies and the flat PDMS as the control were sterilized by using ethanol and then UV exposure, each for $30 \mathrm{~min}$. Prior to cell seeding, the PDMS substrates were incubated with human fibronectin (human, BD Biosciences, $10 \mu \mathrm{g} / \mathrm{ml}$ in PBS) for $15 \mathrm{~min}$.

\subsection{Cell Culture}

Normal human lung fibroblasts (NHLFs, CRL1490 cells from ATCC, Manassas, VA) were cultured in $2 \%$ fetal bovine serum (FBS), $0.1 \%$ recombinant human fibroblast growth factor basic (rhFGF-B), $0.1 \%$ insulin, and $0.1 \%$ gentamicin/amphotecin-B (Lonza). The NHLFs used in the experiments were at passages 3-6.

NHFLs were starved in serum-free medium for $18 \mathrm{hr}$ to induce cell cycle synchronization [53]. Cells were allowed to recover in complete fibroblast medium for $1 \mathrm{hr}$. The cells were seeded at a density of 2000 cells $/ \mathrm{cm}^{2}$ and placed in an incubator for $12 \mathrm{hr}$ to allow the cells to adhere. 


\subsection{Flow Cytometry}

Cells were harvested as a single cell suspension in PBS and fixed in cold $70 \%$ ethanol for $1 \mathrm{hr}$ on ice. Cells were then washed and resuspended in $0.2 \%$ Tween 20 in PBS for 15 min at $37^{\circ} \mathrm{C}$. Cells were washed with 2\% fetal bovine serum in PBS and resuspended in $1.8 \%$ RNas-A in PBS for 15 min at room temperature. Propidium Iodide $(50 \mathrm{ug} / \mathrm{ml})$ in PBS was added for $15 \mathrm{~min}$ at room temperature. After incubation, the volume of each sample was brought up to 500 ul each and analyzed by flow cytometry.

\subsection{Scanning Electron Microscopy (SEM)}

The PDMS substrates containing cells were washed with PBS and fixed for $4 \mathrm{hr}$ in $4 \%$ paraformaldehydeand, $2 \%$ glutaraldehyde at ambient. They were then rinsed with distilled water and progressively dehydrated using a Balzers Critical Point $\mathrm{CO}_{2}$ Dryer, followed by freeze-drying in a graded series of ethanol. Both the PDMS substrates with and without cells grown were sputter-coated with a gold layer of $\sim 10 \mathrm{~nm}$ thick using a Denton Vacuum Desk V sputter unit (Denton Vacuum, LLC, Moorestown, NJ, USA). SEM micrographs were obtained from a JEOL JSM-7600F Scanning Electron Microscope.

\subsection{Atomic force microscopy (AFM)}

AFM characterization was performed using an Asylum MFP-3D Atomic Force Microscope in the tapping mode under ambient conditions. Topography images were recorded simultaneously at the fundamental resonance frequency of the cantilever, with a typical scan rate of $1 \mathrm{~Hz}$ and a resolution of 512 samples per line.

\subsection{Immunofluorescence Staining}

The cells were fixed with $4 \%$ parafomaldehyde in PBS for $15 \mathrm{~min}$ at room temperature, and permeabilized in a blocking solution, which consisted of $0.03 \mathrm{~g} / \mathrm{ml}$ bovine serum albumin (BSA, SigmaAldrich Co.) and 0.1\% goat serum (Sigma-Aldrich Co.) in 0.2\% Triton X-100 (Sigma-Aldrich Co.) in PBS for $30 \mathrm{~min}$. Focal adhesions were stained by using anti-paxillin antibody (1:200; Abcam, Cambridge, MA, USA) followed by the Alexa Fluor 555 goat anti-rabbit secondary antibody (1:200; Invitrogen, Carlsbad, CA, USA). F-actin was stained with Alexa Fluor 488 phalloidin (Invitrogen, Carlsbad, CA, 
USA), and the cell nuclei were stained and mounted using ProLong Gold Antifade Reagent with DAPI (Life Technologies) and viewed with Zeiss LSM 510 inverted confocal microscope.

For the nuclear volume measurement, z-stack imaging with $0.1 \mu \mathrm{m}$ intervals between planar images was conducted. To validate the accuracy of z-stack imaging of nuclei, FITC-labelled beads (diameter: $15.4 \mathrm{um} \pm 0.13 \mathrm{um}, \mathrm{BD}$ Bioscience) were used as the standard.

\subsection{Image Analysis}

Focal adhesion size and nuclear area and volume were analyzed using Imaris. Briefly, creating superficial surfaces overlaying the image; the threshold was set to the TRITC channel and was adjusted to fit the parameters of the confocal image; particles of sizes between 2 and $10 \mu \mathrm{m}^{2}$ were extracted using a filter and analyzed.

\subsection{Statistical Analysis}

Focal adhesion size and nuclear deformation in terms of projected area and volume of NHFLs were presented as mean \pm standard error. Approximately 150-200 nuclei images from each of three replicates were collected for each condition. Approximately 1000 focal adhesions for each condition were analyzed from 15-20 cells from each nanotopographies incuding the flat control. The differences between groups were analyzed by one-way ANOVA and Dunnet's method, with $\mathrm{P}<0.05$ taken as statistically significant. 


\section{Res ults and Dis cus sion}

\subsection{Design of Nanotopographies}

Nanoscale gratings and pillars were of interest because they represented two major nanotopographies.

Nanogratings (NGs) would provide anisotropic guidance to cells, while hexagonally arranged nanopillars (NPs) were isotropic. The lateral dimensions of nanotopographies were controlled by EBL writing and the feature height was defined by the thickness of the PMMA thin film. The linewidth of nanogratings were 300, 500 and $1000 \mathrm{~nm}$ and the edge-to-edge spacings were 1 and 3 times the linewidth for each design (Fig. 1.1A). The pillars had the diameter of 300, 500, $1000 \mathrm{~nm}$ and a center-to-center spacing of 1.3 and 1.9 times the diameter. The corresponding edge-to-edge distances were 90,150 and $300 \mathrm{~nm}$ for the $1 \mathrm{X}$ spacing pillars and 270, 450 and $900 \mathrm{~nm}$ for $3 \mathrm{X}$ spacing (Fig. 1.1B). The height of all nanotopographies was $170 \mathrm{~nm}$ as measured by using AFM (Fig. 1.1C). To facilitate the discussion, each nanotopography was named by using its abbreviation (NG or NP) followed by a combination of the feature size (linewidth for nanogratings and diameter for nanopillars) and the spacing. For instance, 'NG 500-3X' stood for the nanogratings of $500 \mathrm{~nm}$ in linewidth and $1500 \mathrm{~nm}$ for spacing, and 'NP 500-1.9X' for the nanopillars of $500 \mathrm{~nm}$ in diameter and $950 \mathrm{~nm}$ for the center-to-center spacing (or $450 \mathrm{~nm}$ for the edge-to-edge distance). For each feature size, the spacing was chosen to keep the ratio of the nanostructured surface area over the total area of the corresponding flat surface constant. For example, when the spacing of nanogratings was the same as the linewidth the ratio was 0.50 . The increase of the spacing of nanogratings from $1 \mathrm{X}$ to $3 \mathrm{X}$ the linewidth decreased the ratio to 0.25 . Similarly, the increase of the center-to-center spacing from $1.3 \mathrm{X}$ to $1.9 \mathrm{X}$ the diameter decreased the ratio from 0.50 to 0.25 . Hence, the featured surface area could be kept constant so that the cells may be exposed to the same seeding area but at the same time to different topography. 
A
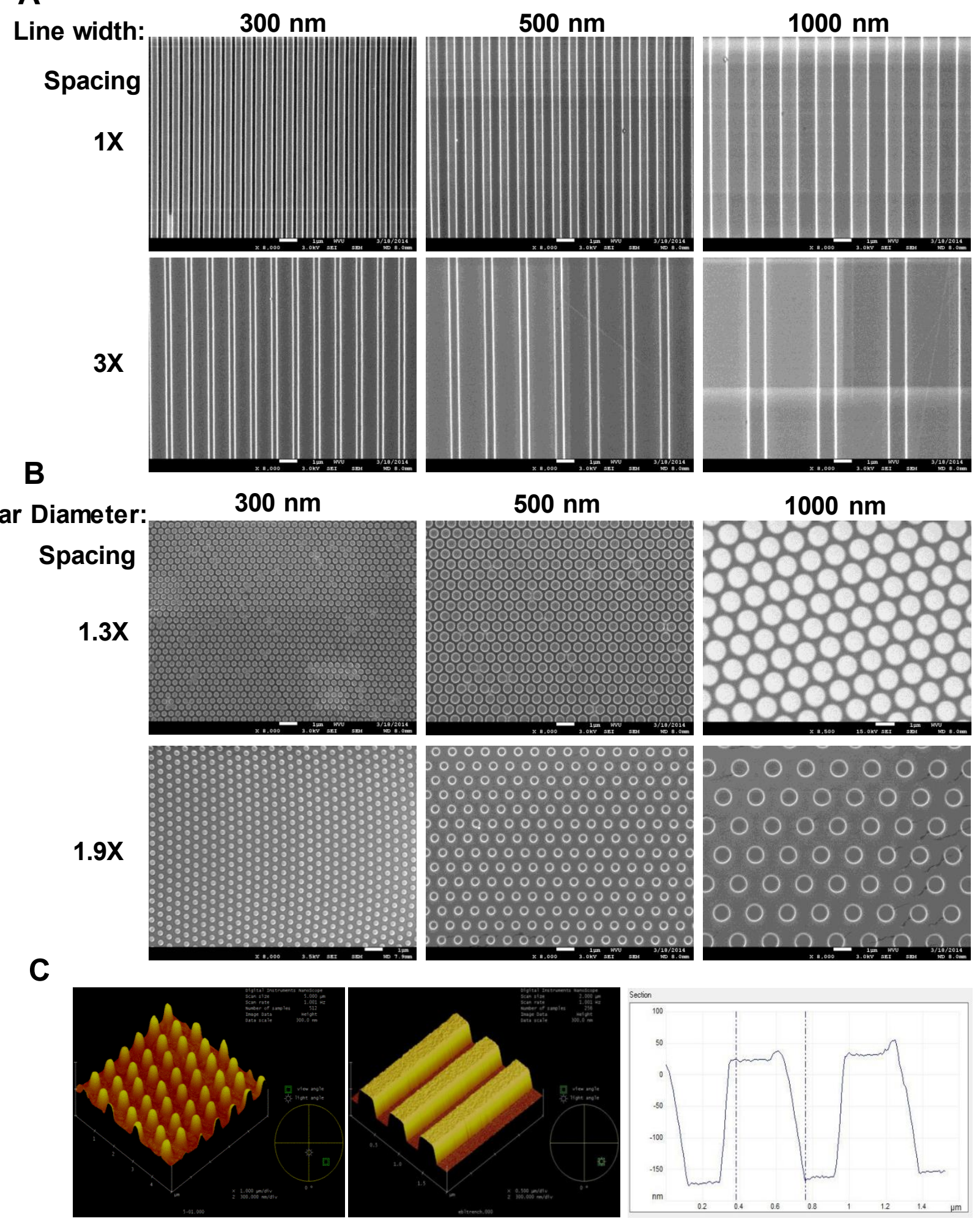

Figure 1.1: A) SEM micrographs of (A) nanogratings, (B) nanoposts, and (C) AFM images of typical nanotopographies. Two-dimensional profile indicated the feature height. 


\subsection{Spacing-dependent Cell Alignment on Nanogratings}

Normal human lung fibroblasts (NHLFs) were serum starved for $18 \mathrm{hr}$ to give rise to a larger than $92 \%$ population of cells possessing a synchronized nuclear cycle, G1 phase, substantially reducing the variation in starting nuclear volume. After the cell adheres onto the substrate, increasing intracellular tension may mature early stage focal complexes into focal adhesions, which can reach several micrometers in length. It was reported that focal adhesions of MC3T3-E1 preosteoblasts grew in length from $4 \mathrm{hr}$ to $12 \mathrm{hr}$ culture [47]. We were interested in the early-stage cell-nanotopography interactions and hence investigated the cell responses at $12 \mathrm{hr}$. Shown in Fig. 1.2, NHLFs displayed multipolar morphology on the nanopillars, similar to those on the control flat surfaces; while the cells might orient along the nanogratings direction.
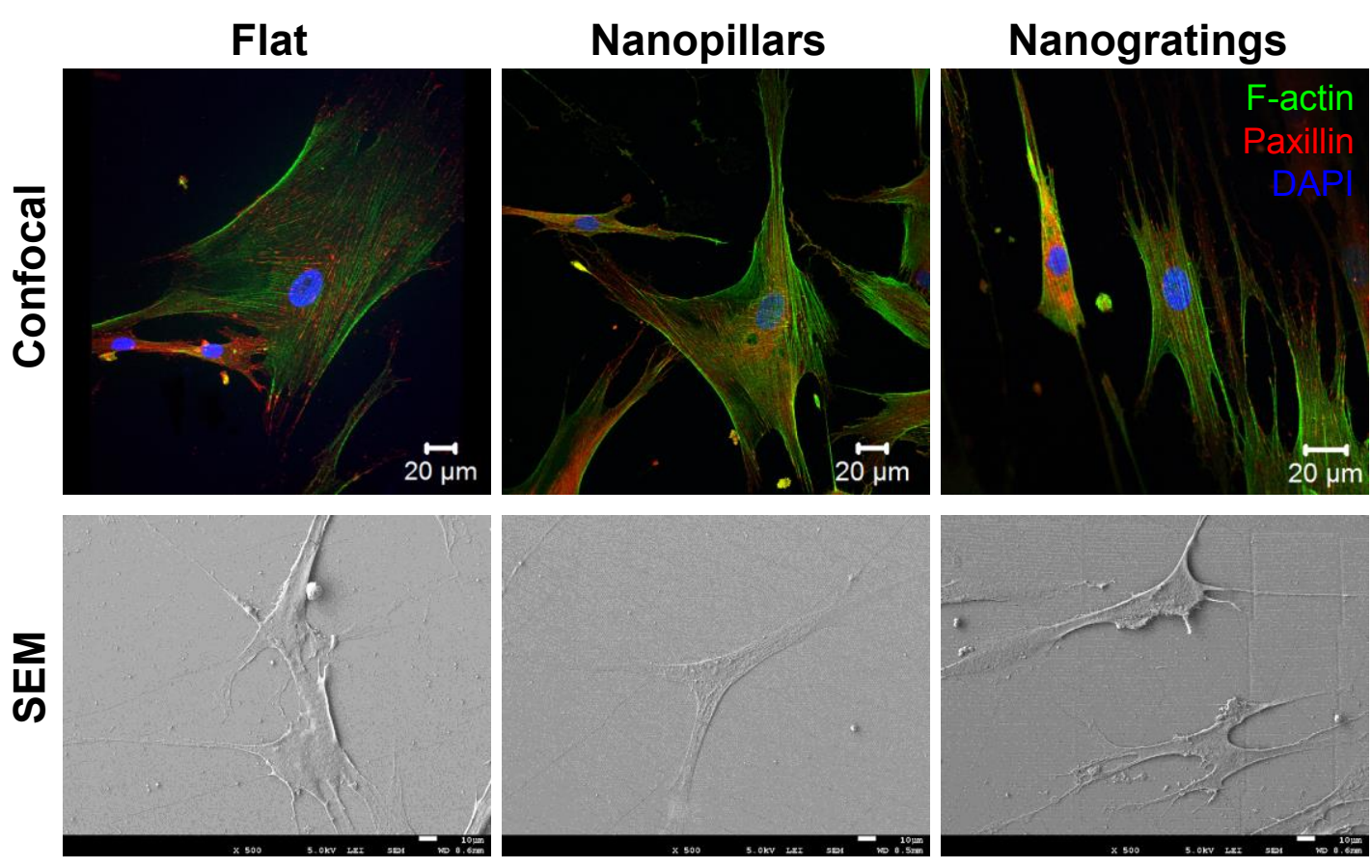

Figure 1.2: Nanotopography-dependent cell spreading. The nuclei were stained with DAPI in blue, the actin filaments were stained with phalloidin in green, and focal adhesions were stained with paxillin in red. 
It has been observed that nanogratings could provide contact guidance for cells to align along the nanogratings direction $[11,20,25,26,28-32]$. Surprisingly, NHFLs did not align on all nanogratings studied. As shown in Fig. 1.3A, the cells did not display obvious alignment preference when the nanogratings had the same spacing as the linewidth. On the other hand, the cells preferentially oriented along the nanogratings direction when the spacing was $3 \mathrm{X}$ the linewidth for all three linewidths studied. We further examined the cell spreading using SEM (Fig. 1.3B). The cells seemed to stay on NG 300-1X, but could reach the bottom of the grooves for the other five nanogratings. When the spacing was $1 \mathrm{X}$ linewidth, the filopodia could reach out perpendicular to the grating direction (NG 500-1X and NG 10001X), while the filopodia of the cells on NG 300-3X and NG 500-3X preferred to extend along the grating direction. In our nanotopography design, the feature height was $170 \mathrm{~nm}$. The cells could overcome the grating barrier and reach the neighboring gratings when the spacing was narrow. When the spacing was three times the linewidth, it might be easier for the cell to follow contact guidance and to orient along the gratings. When the spacing was further increased, i.e. $3000 \mathrm{~nm}$ for NG 1000-3X, the lamellipodia could reach the groove bottom and the filopodia could extend perpendicular to the grating direction. Both confocal and SEM observations suggested that although nanogratings might provide contact guidance the human fibroblasts could bridge the gaps and did not show preferential orientation when the spacing was narrow. When the spacing was signific antly increased, however, it may be easier for the cells to elongate along the ridge. Therefore, the nanograting-induced cell orientation is spacing dependent. 
A
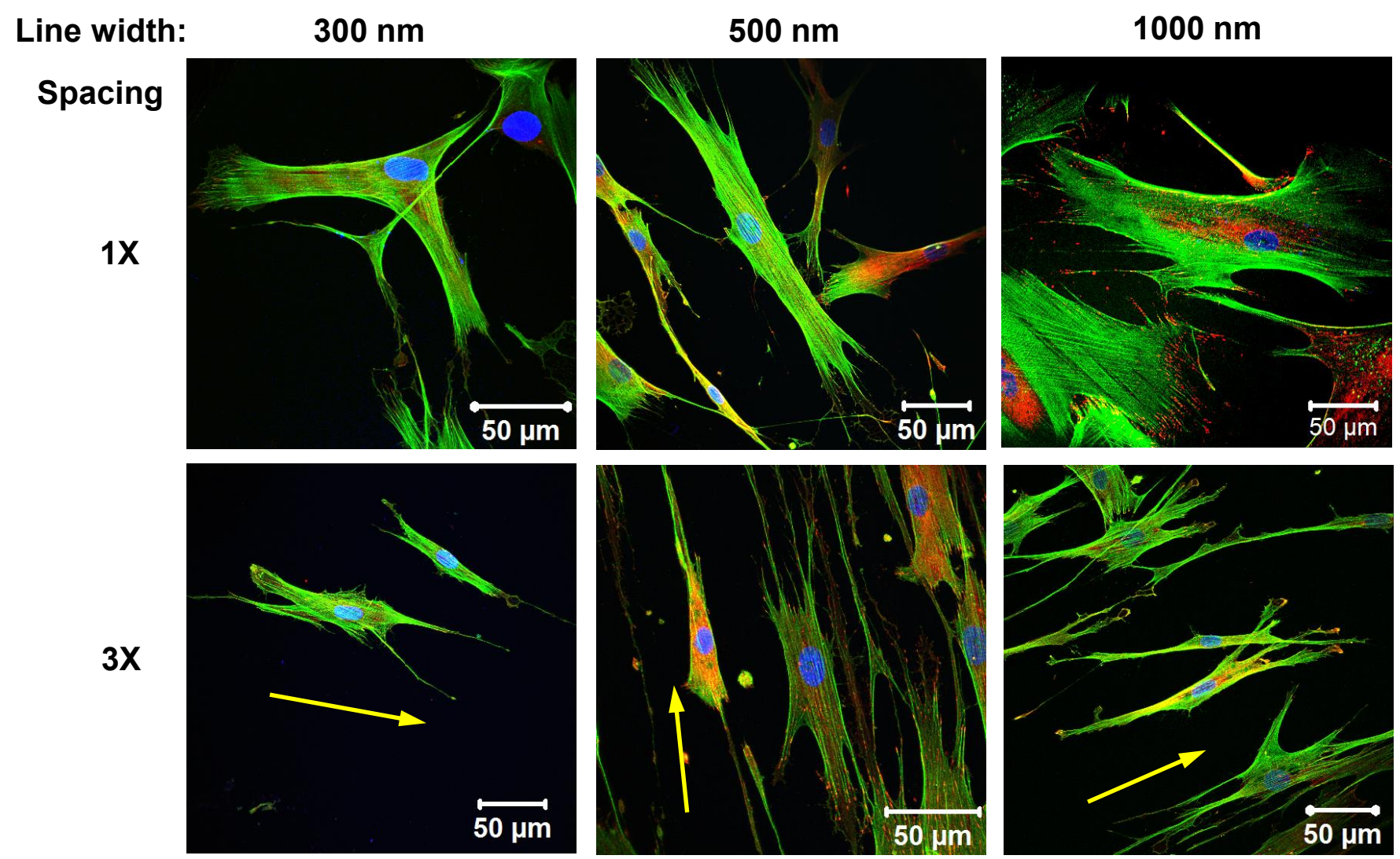

B

\section{Line width:}

$300 \mathrm{~nm}$
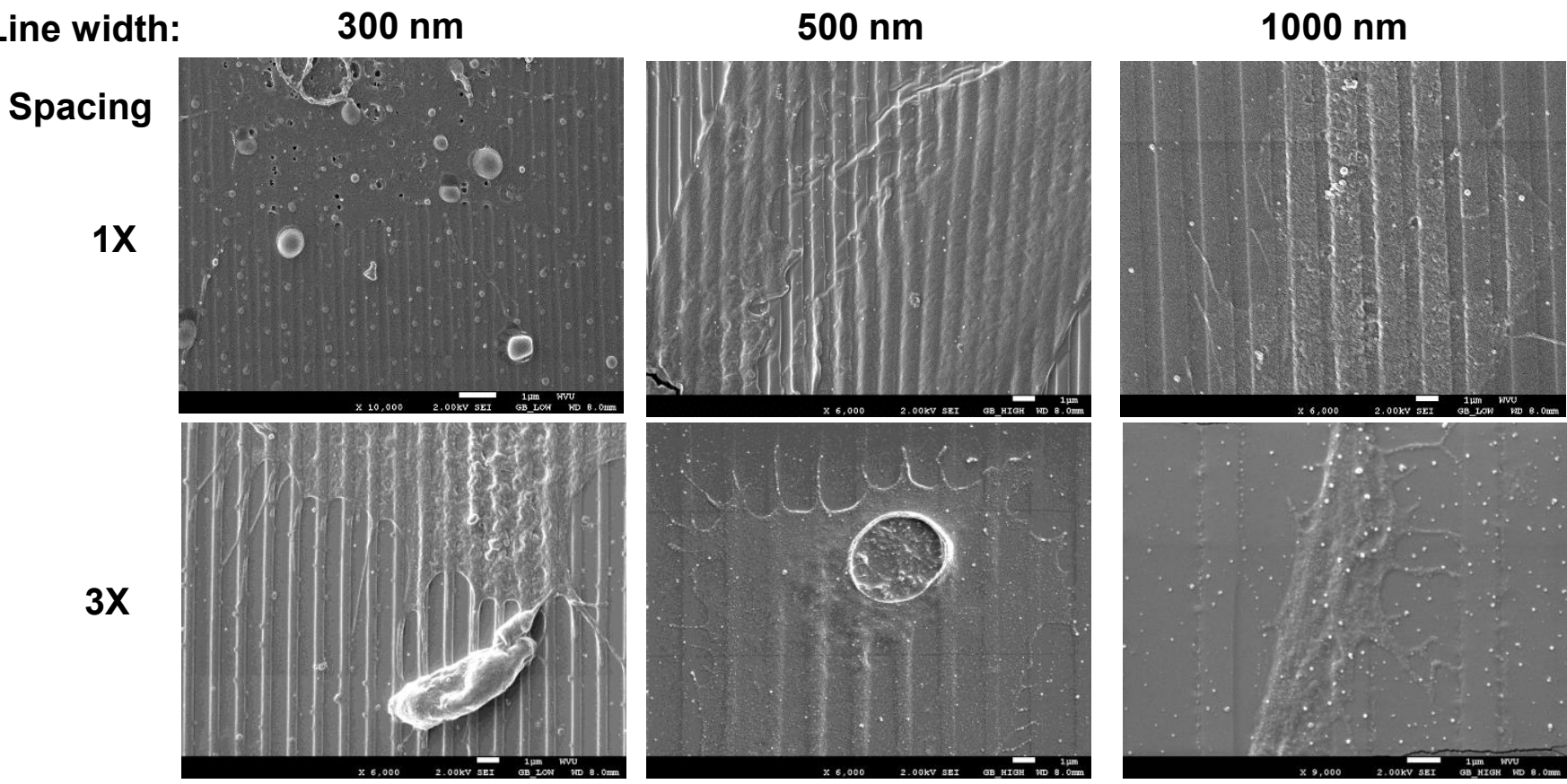

Figure 1.3: Cell spreading on nanogratings. A) Confocal and B) SEM images of NHLFs grown on nanogratings. The yellow arrows point to the nanograting direction. Scale bars $=1 \mu \mathrm{m}$. 


\subsection{Nanogratings Modulated Focal Adhesions and Nuclear Size}

As the first step for the adhesion-cytoskeleton-nucleus mechanotransduction pathway, focal adhesions of cells in response to nanotopographies were examined. We analyzed confocal images for focal adhesion protein paxillin in the cells on the nanogratings and the flat surface, and compared structures between 2 and $10 \mu \mathrm{m}^{2}$, the typical size for mature focal adhesions [50]. The focal adhesion structures in the highmagnification confocal images (Fig. 1.4A) were extracted using Imaris (Fig. 1.4B) and the focal adhesions were analyzed.
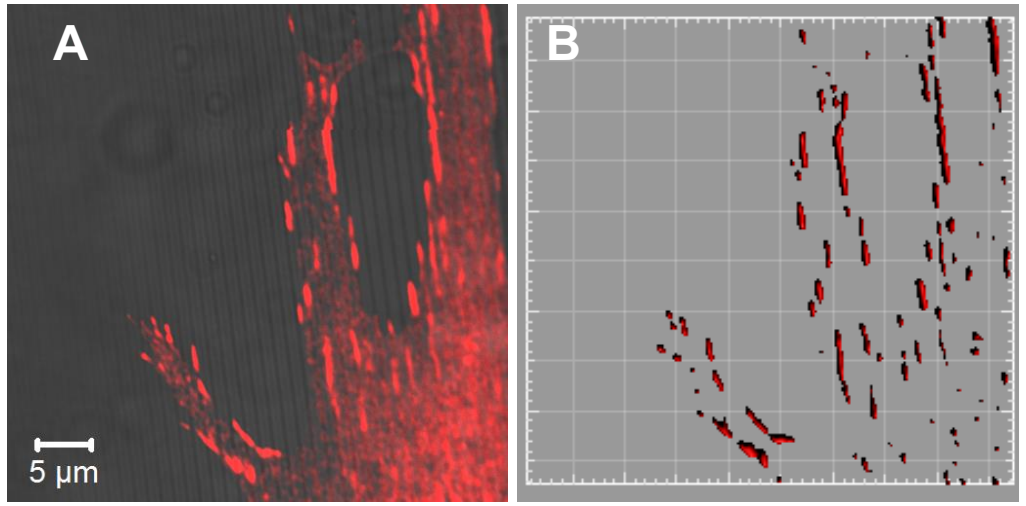

Figure 1.4: Image analysis using Imaris. The confocal images of focal adhesion protein paxillin structures on (A) nanogratings were extracted using Imaris after applying threshold and shown in (B).

Nanotopography can increase the total surface area, depending on the shape and size of the features. We defined the ratio of total surface area versus the corresponding flat surface to reflect the extent of nanotopography-induced increase in the surface area. Fig. 1.5 showed that when the ratio was low (all nanogratings except NG 300-1X) there was no obvious difference in the average focal adhesion size betw een the nanogratings and the flat control, $4.6 \pm 0.1 \mu \mathrm{m}^{2}$. However, the average focal adhesion size of cells on NG 300-1X was significantly smaller than the flat control. The spacing of NG 300-1X was 300 $\mathrm{nm}$ while other nanogratings had spacing larger than $500 \mathrm{~nm}$, indicating that there was a critical spacing of between 300 and $500 \mathrm{~nm}$. This observation agreed well with the previous report that the cells could fill 800-nm gratings completely but not reach of bottom of 400-nm gratings [51]. The results suggested that 
nanogratings may affect the focal adhesion size, depending on not only the surface area increase but also the spacing.

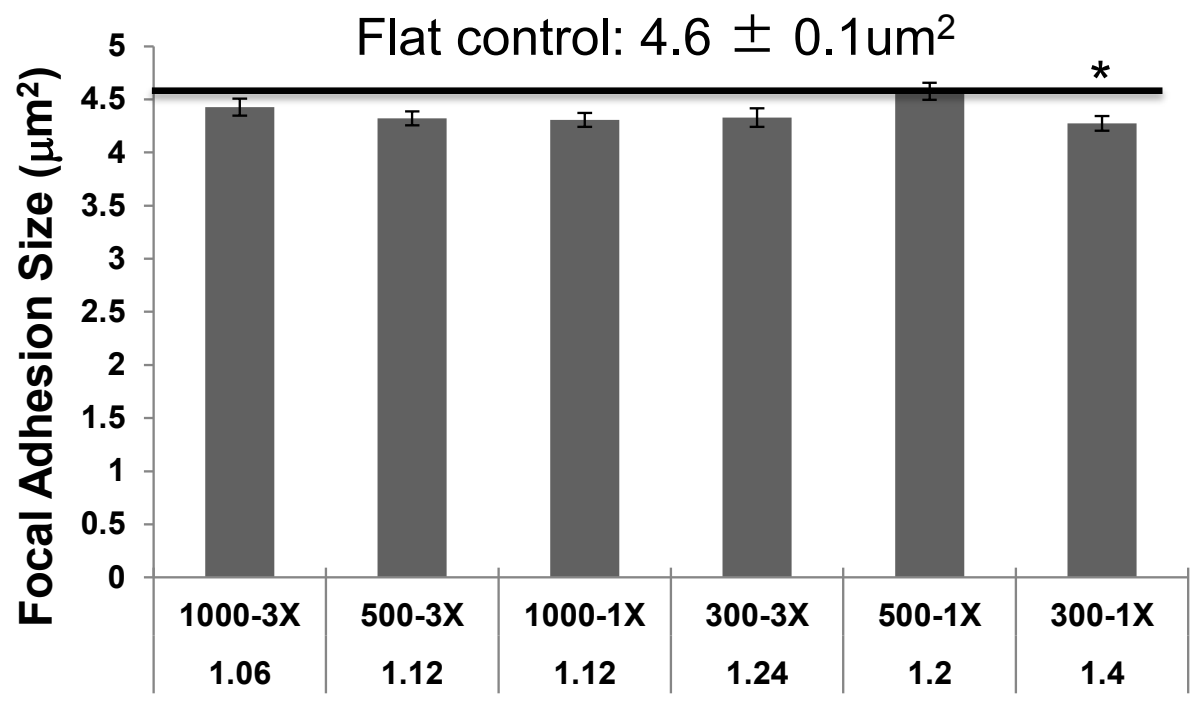

Total Surface Area/Flat Surface

Figure 1.5: Nanogratings-modulated focal adhesion size. The straight horizontal line indicated the average focal adhesion size of NHLFs on the flat control.

Of particular interest was the nuclear deformation, which would result in changes of gene and protein expression $[42,43]$ and was strongly associated with cell proliferation and differentiation $[45,46]$. To validate the accuracy of the confocal z-stack measurement of nuclear volume, we measured the FITCspheres with a diameter of $15.4 \pm 0.13 \mu \mathrm{m}^{2}$ which were embedded in collagen I gel. The measured sphere volume was $1893.8 \pm 71 \mu^{3}$, which agreed well with the calculated volume of $1912.3 \pm 56 \mu \mathrm{m}^{3}$ (measurement error $<1 \%$ ). The nuclei confocal images were reconstructed in Imaris and nuclei area and volume were analyzed (Figure 1.6). Compared to the nuclear area and volume on the flat surface, the cells displayed larger nuclear area (Fig. 1.7A) and volume (Fig. 1.7B) on all nanogratings except on NG 3003X. McKee et al. measured the nuclear deformation and nuclear elastic modulus of human corneal 
epithelial cells grown on equally spaced nanogratings with a pitch from $400 \mathrm{~nm}$ to $2000 \mathrm{~nm}$ and a constant depth of $300 \mathrm{~nm}$. They found that the nuclear volume increased as the pitch of nanogratings increased from $400 \mathrm{~nm}$ to $2000 \mathrm{~nm}$. The $400-\mathrm{nm}$ nanogratings resulted in the smallest volume and other nanogratings had higher nuclear volume than the flat surface. The elastic modulus of aligned cells was nanograting-dependent, but not simply increased with increasing pitch size [48]. This differences were believed to be resulted from several issues. McKee et al. did not eliminate the variation by synchronizing the cell cycle. They only measured six cells, which might not represent the average response from the whole cell population. Different cell types studied might be another factor. Nanogratings, very often, reduced the surface area cells can sense, which can result in a decrease cell spreading and proliferation although the cell alignment, elongation and migration are enhanced [11,24,29-33]. In the present study, NHLFs spread less on nanogratings but had increasing nuclear volume for all but one pattern.
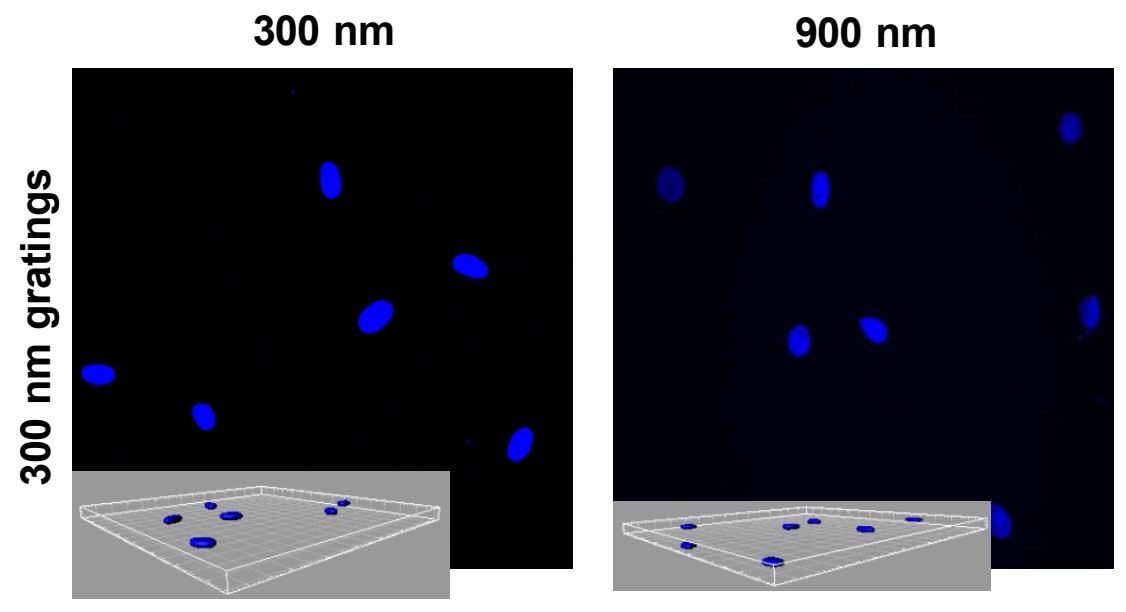

Figure 1.6: Typical projected nuclear area and reconstructed nuclear volume of cells on nanogratings. 

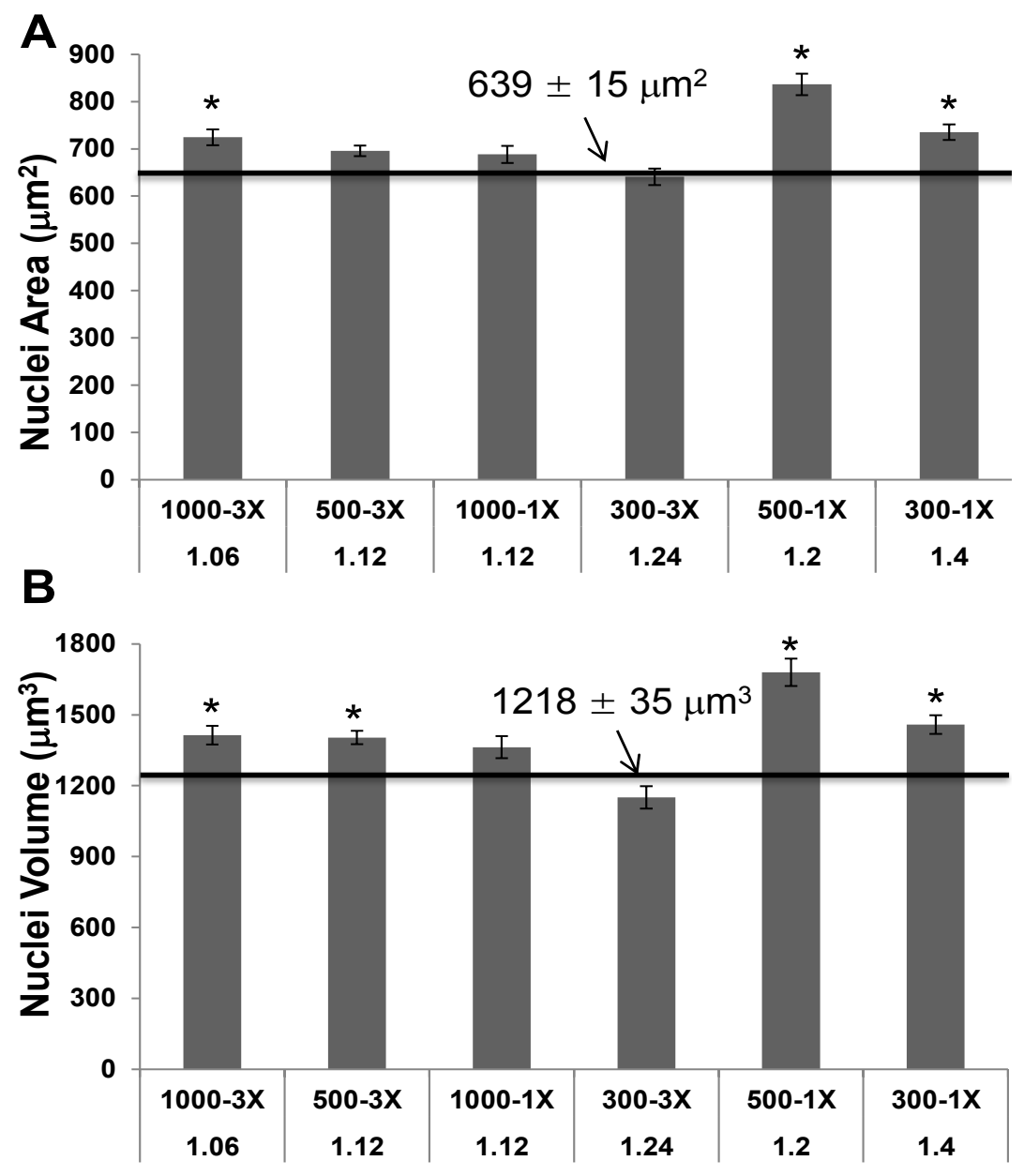

\section{Total Surface Area/Flat Surface}

Figure 1.7: Nuclear deformation on nanotopographies. (A) Nuclear area and (B) nuclear volume comparison of cells grown on nanogratings. The straight horizontal lines indicated the average nuclear area and volume of NHLFs on the flat control. 


\subsection{Cellular Responses to Nanoposts}

Different from nanogratings, NHFLs spread in all directions on nanopillars. Except for NP 300-1.3X where the PDMS pillars were densely packed and collapsed into bigger aggregates because of dimensional instability, the cells could confine on the pillars and the filopodia extension on the top of the pillars for both small $(300 \mathrm{~nm})$ and large $(1000 \mathrm{~nm})$ pillars (Fig. 1.8). Focal adhesion protein paxillin displayed random orientation on the isotropic pillars (Fig. 9). Image analysis of focal adhesions showed that the average focal adhesion size was smaller than that on the flat control (Fig. 1.10). In particular, the focal adhesion size on NP 500-1.9X was significantly smaller than the flat control.
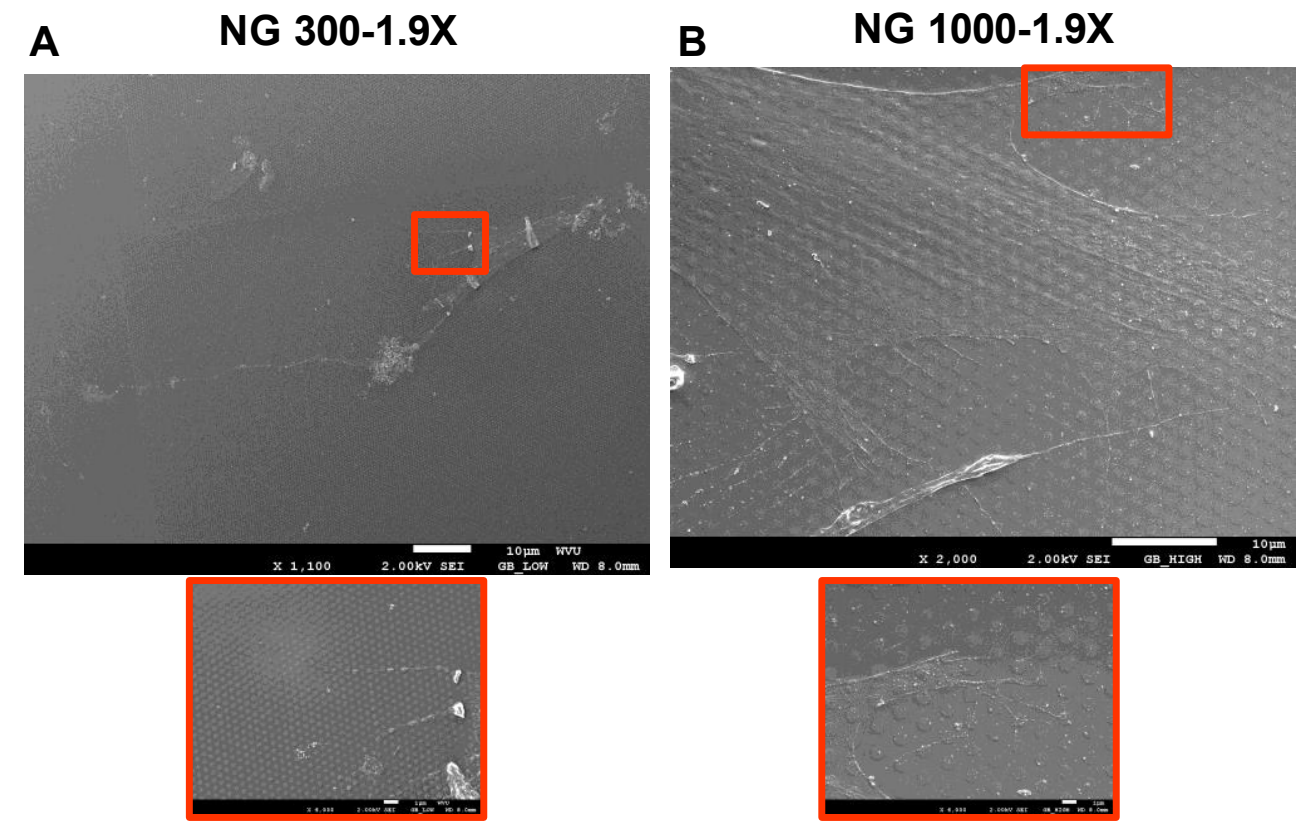

Figure 1.8: SEM micrographs of human fibroblasts grown on (A) nanopillars 300-1.9X and (B) nanopillars 1000-1.9X. The boxed regions were enlarged to show the filopodia extension. 

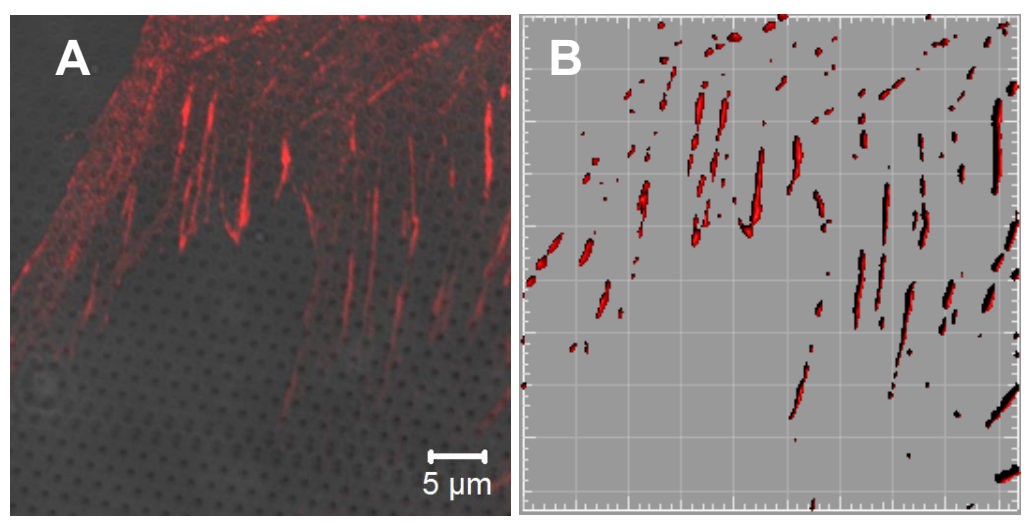

Figure 1.9: Image analysis using Imaris. The confocal images of focal adhesion protein paxillin structures on (A) nanogratings were extracted using Imaris after applying threshold and shown in $(\mathbf{B})$.

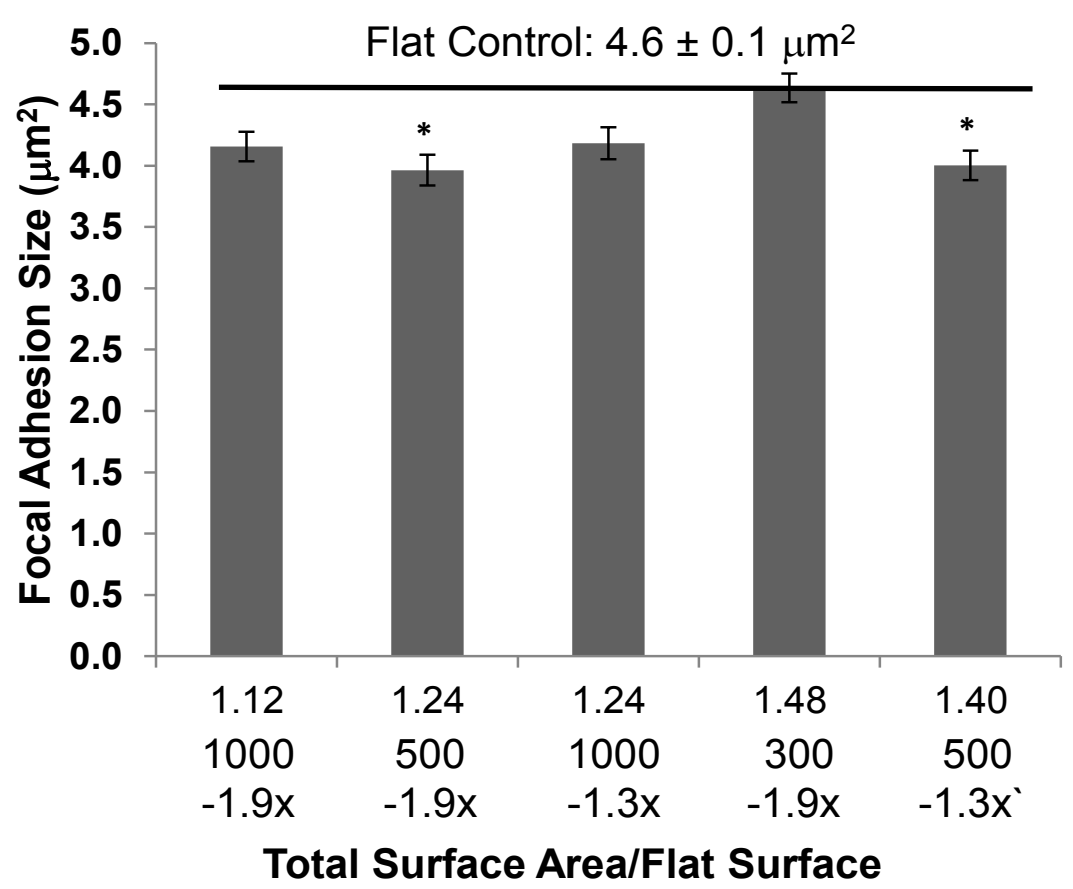

Figure 1.10: Nanopillars-modulated average focal adhesion size. 
Interestingly, the cells on NP 500-1.9X displayed a larger nuclear volume than that on the flat surface (Fig. 1.11). In NP 500-1.9X, the edge-to-edge distance of $450 \mathrm{~nm}$ was large enough so that the cells would completely confine to the space and thus the nanopillar-induced total surface area increase enhanced cell spreading. When the spacing was further increased to $900 \mathrm{~nm}$ of NP $1000-1.9 \mathrm{X}$, the increase in surface area and cell spreading was not significant. Therefore, the nuclear volume increased in NP 500-1.9X. When the edge-to-edge distance was smaller than $300 \mathrm{~nm}$ (NP 1000-1.3X, NP 300-1.9X and NO 500-1.3X) the cells might not see obvious difference between the nanopillars and the flat surface and the nuclear volume was almost the same.

Correlation between focal adhesions and nuclear volume was also analyzed. There was no significant difference in the average focal adhesion size and nuclear volume of the cells on nanogratings (except NG 300-1X) and the flat surface. However, NP 500-1.9X enhanced cell spreading, and consequently increased the nuclear volume. Roca-Cusachs et al. suggested that cell spreading promoted DNA synthesis by inducing nuclear swelling, thereby induced an increase in proliferation, actin polymerization (F-actin content), and stress fiber formation, whereas elongation dramatically affected entanglement and bending of actin filaments but had little or no effect on proliferation, formation of stress fibers, and F-actin content [46].

It was noted that some nanotopography had smaller focal adhesions size but bigger nuclear volume. For example, the cells on NP 500-1.9X had significantly smaller average focal adhesion size than the flat control but the correspondent nuclear volume was significantly larger than that on the flat surface. We postulated that the quantity of total focal adhesions instead of the average focal adhesion size determined cell spreading and thus nuclear volume. Jean et al. measured nuclear deformation in response to alterations of cell shape as cells detach from a flat surface. They found that the nuclear deformation appeared to be in direct and immediate response to alterations of the cell adhesion area [52]. As a matter of fact, it was observed that the cells were easier to detach from nanogratings than the flat surface during the cell fixation process. 

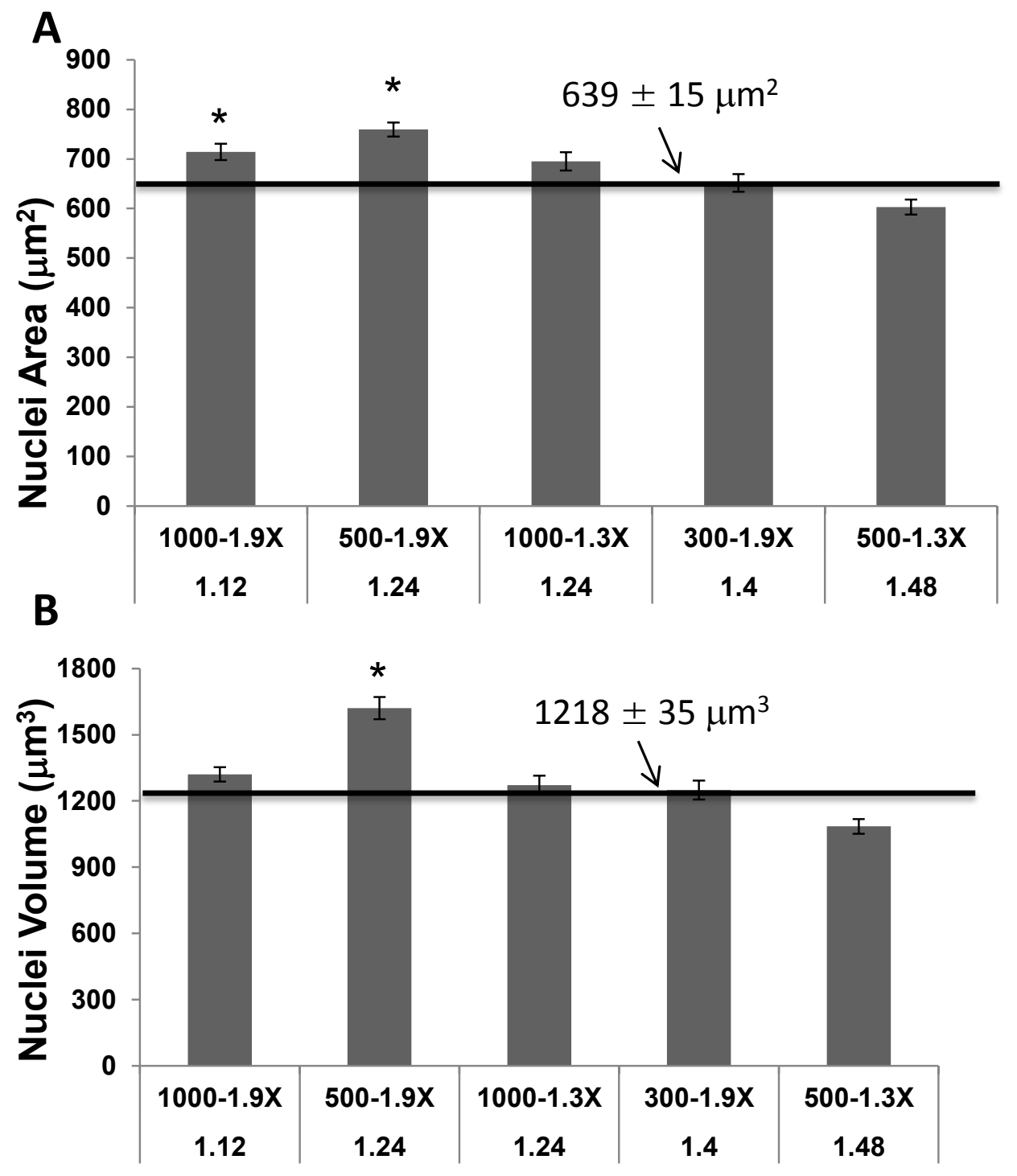

Total Surface Area/Flat Surface

Figure 1.11: Nanopillar modulated deformation of (A) nuclear area and (B) nuclear volume of fibroblasts. 


\section{Conclusion}

Focal adhesions and nuclear deformation of NHFLs in response to a variety of nanotopographies have been investigated. It was found that the orientation of the focal adhesions and nuclei along the nanogratings depended on not only the linewidth but also the spacing. Nanogratings, in general, hindered cell spreading and thus reduced the cell size while increasing the nuclear size. On the other hand, nanopillars, depending on the feature size and spacing, might modulate the focal adhesions and nuclear tow ards opposite directions. Our observations also suggested that it was focal adhesion area instead of the focal adhesion size that determined the cell spreading and nuclear deformation. Taken together, nanotopography could be optimized to modulate the cell adhesions and nuclear volume, which provide the useful tool to regulate cells for the end applications. 


\section{Re fe re nces}

1.Petit-Zeman S (2001) Regenerative medicine. Nature Biotechnology 19: 201-206.

2. Even-Ram S, Artym V, Yamada Kenneth M (2006) Matrix control of stem cell fate. Cell 126: 645-647.

3. Mwenifumbo S, Stevens MM (2008) ECM interactions with cells from the macro- to nanoscale. In: Gonsalves K, Halberstadt C, Laurencin CT, Nair L, editors. Biomedical Nanostructures. 1 ed: Wiley-Interscience. pp. 225-260.

4. Flemming RG, Murphy CJ, Abrams GA, Goodman SL, Nealey PF (1999) Effects of synthetic microand nano-structured surfaces on cell behavior. Biomaterials 20: 573-588.

5. Shirato I, Tomino Y, Koide H, Sakai T (1991) Fine structure of the glomerular basement membrane of the rat kidney visualized by high-resolution scanning electron microscopy. Cell and Tissue Research 266: 1-10.

6. Hironaka K, Makino H, Yamasaki Y, Ota Z (1993) Renal basement membranes by ultrahigh resolution scanning electron microscopy. Kidney international 43: 334-345.

7. Abrams GA, Goodman SL, Nealey PF, Franco M, Murphy CJ (2000) Nanoscale topography of the basement membrane underlying the corneal epithelium of the rhesus macaque. Cell and Tissue Research 299: 39-46.

8. Gong H, Freddo TF, Johnson M (1992) Age-related changes of sulfated proteoglycans in the normal human trabecular meshwork. Experimental Eye Research 55: 691-709.

9. Liliensiek SJ, Nealey P, Murphy CJ (2009) Characterization of endothelial basement membrane nanotopography in rhesus macaque as a guide for vessel tissue engineering. Tissue Eng Part A 15: 2643-2651.

10. Silva GA, Czeisler C, Niece KL, Beniash E, Harrington DA, et al. (2004) Selective differentiation of neural progenitor cells by high-epitope density nanofibers. Science 303: 1352-1355.

11. Yim EKF, Pang SW, Leong KW (2007) Synthetic nanostructures inducing differentiation of human mesenchymal stem cells into neuronal lineage. Experimental Cell Research 313: 1820-1829.

12. Dalby MJ, Gadegaard N, Tare R, Andar A, Riehle MO, et al. (2007) The control of human mesenchymal cell differentiation using nanoscale symmetry and disorder. Nature Materials 6: 997-1003.

13. Oh S, Brammer KS, Li YSJ, Teng D, Engler AJ, et al. (2009) Stem cell fate dictated solely by altered nanotube dimension. Proceedings of the National Academy of Sciences of the United States of America 106: 2130-2135.

14. Lee MR, Kwon KW, Jung H, Kim HN, Suh KY, et al. (2010) Direct differentiation of human embryonic stem cells into selective neurons on nanoscale ridge/groove pattern arrays. Biomaterials 31:4360-4366. 
15. Moe AAK, Suryana M, Marcy G, Lim SK, Ankam S, et al. (2012) Microarray with Micro- and Nanotopographies Enables Identification of the Optimal Topography for Directing the Differentiation of Primary Murine Neural Progenitor Cells. Small: n/a-n/a.

16. Dang JM, Leong KW (2007) Myogenic induction of aligned mesenchymal stem cell sheets by culture on thermally responsive electrospun nanofibers. Advanced Materials 19:2775-2779.

17. Ridley AJ, Schwartz MA, Burridge K, Firtel RA, Ginsberg MH, et al. (2003) Cell Migration: Integrating Signals from Front to Back. Science 302: 1704-1709.

18. Craighead HG, Turner SW, Davis RC, James C, Perez AM, et al. (1998) Chemical and topographical surface modification for control of central nervous system cell adhesion. Biomedical Microdevices 1: 49-64.

19. Lim JY, Hansen JC, Siedlecki CA, Runt J, Donahue HJ (2005) Human foetal osteoblastic cell response to polymer-demixed nanotopographic interfaces. Journal of the Royal Society, Interface 2: $97-108$.

20. Teixeira AI, Abrams GA, Bertics PJ, Murphy CJ, Nealey PF (2003) Epithelial contact guidance on well-defined micro- and nanostructured substrates. Journal of Cell Science 116: 1881-1892.

21. Ohara PT, Buck RC (1979) Contact guidance in vitro : A light, transmission, and scanning electron microscopic study. Experimental Cell Research 121: 235-249.

22. Dalby MJ, Riehle MO, Johnstone H, Affrossman S, Curtis ASG (2002) In vitro reaction of endothelial cells to polymer demixed nanotopography. Biomaterials 23: 2945-2954.

23. Dalby MJ, Marshall GE, Johnstone HJH, Affrossman S, Riehle MO (2002) Interactions of human blood and tissue cell types with 95-nm-high nanotopography. IEEE transactions on nanobioscience 1: 18-23.

24. Dalby MJ, Marshall George E, Johnstone Heather JH, Affrossman S, Riehle Mathis O (2002) Interactions of human blood and tissue cell types with 95-nm-high nanotopography. IEEE transactions on nanobioscience 1: 18-23.

25. Hu W, Yim EKF, Reano RM, Leong KW, Pang SW (2005) Effects of nanoimprinted patterns in tissue-culture polystyrene on cell behavior. Journal of Vacuum Science \& Technology, B Microelectronics and Nanometer Structures--Processing, Measurement, and Phenomena 23: 2984-2989.

26. Yang Y, Kulangara K, Sia J, Wang L, Leong K (2011) Engineering of a microfluidic cell culture platform embedded with nanoscale features. Lab on a Chip 11: 1638-1646.

27. Frey MT, Tsai IY, Russell TP, Hanks SK, Wang YL (2006) Cellular responses to substrate topography: role of myosin II and focal adhesion kinase. Biophysical Journal 90: 3774-3782.

28. Kulangara K, Yang Y, Yang J, Leong KW (2012) Nanotopography as modulator of human mesenchymal stem cell function. Biomaterials 33: 4998-5003.

29. Yim EKF, Reano RM, Pang SW, Yee AF, Chen CS, et al. (2005) Nanopattern-induced changes in morphology and motility of smooth muscle cells. Biomaterials 26: 5405-5413. 
30. Gerecht S, Bettinger CJ, Zhang Z, Borenstein JT, Vunjak-Novakovic G, et al. (2007) The effect of actin disrupting agents on contact guidance of human embryonic stem cells. Biomaterials 28: 4068-4077.

31. Bettinger CJ, Zhang Z, Gerecht S, Borenstein JT, Langer R (2008) Enhancement of in vitro capillary tube formation by substrate nanotopography. Advanced Materials 20: 99-103.

32. Lenhert S, Meier M-B, Meyer U, Chi L, Wiesmann HP (2005) Osteoblast alignment, elongation and migration on grooved polystyrene surfaces patterned by Langmuir-Blodgett lithography. Biomaterials 26: 563-570.

33. Thakar RG, Ho F, Huang NF, Liepmann D, Li S (2003) Regulation of vascular smooth muscle cells by micropatterning. Biochemical and Biophysical Research Communications 307: 883-890.

34. McMurray R, Gadegaard N, Tsimbouri P, Burgess K, McNamara L, et al. (2011) Nanoscale surfaces for the long-term maintenance of mesenchymal stem cell phenotype and multipotency. Nature Materials 10: 637-644.

35. Thomas $\mathrm{CH}$, Collier JH, Sfeir CS, Healy KE (2002) Engineering gene expression and protein synthesis by modulation of nuclear shape. Proc Natl Acad Sci U S A 99: 1972-1977.

36. Maniotis AJ, Chen CS, Ingber DE (1997) Demonstration of mechanical connections between integrins, cytoskeletal filaments, and nucleoplasm that stabilize nuclear structure (cell mechanics/cell engineering/tensegrity/extracellular matrix/mechanotransduction). Proc eedings of the National Academy of Sciences of the United States of America 94: 849-854.

37. Khatiwala CB, Peyton SR, Putnam AJ (2006) Intrinsic mechanical properties of the extracellular matrix affect the behavior of pre-osteoblastic MC3T3-E1 cells. Am J Physiol Cell Physiol 290: C1640-1650.

38. Kong HJ, Polte TR, Alsberg E, Mooney DJ (2005) FRET measurements of cell-traction forces and nano-scale clustering of adhesion ligands varied by substrate stiffness. Proceedings of the National Academy of Sciences of the United States of America 102: 4300-4305.

39. Wang N, Tolic-Norrelykke IM, Chen J, Mijailovich SM, Butler JP, et al. (2002) Cell prestress. I. Stiffness and prestress are closely associated in adherent contractile cells. American Journal of Physiology 282: C606-C616.

40. McBride SH, Knothe Tate ML (2008) Modulation of Stem Cell Shape and Fate A: The Role of Density and Seeding Protocol on Nucleus Shape and Gene Expression. Tissue Engineering, Part A 14: 1561-1572.

41. Dahl KN, Ribeiro AJ, Lammerding J (2008) Nuclear shape, mechanics, and mechanotransduction. Circ Res 102: 1307-1318.

42. Dalby MJ, Riehle MO, Yarwood SJ, Wilkinson CDW, Curtis ASG (2003) Nucleus alignment and cell signaling in fibroblasts: response to a micro-grooved topography. Experimental Cell Research 284: $274-282$. 
43. Thomas CH, Collier JH, Sfeir CS, Healy KE (2002) Engineering gene expression and protein synthesis by modulation of nuclear shape. Proceedings of the National Academy of Sciences of the United States of America 99: 1972-1977.

44. Chalut KJ, Kulangara K, Giacomelli MG, Wax A, Leong K-W (2010) Deformation of stem cell nuclei by nanotopographical cues. Soft Matter 6: 1675-1681.

45. Pajerowski JD, Dahl KN, Zhong FL, Sammak PJ, Discher DE (2007) Physical plasticity of the nucleus in stem cell differentiation. Proceedings of the National Academy of Sciences of the United States of America 104: 15619-15624.

46. Roca-Cusachs P, Alcaraz J, Sunyer R, Samitier J, Farre R, et al. (2008) Micropatterning of single endothelial cell shape reveals a tight coupling between nuclear volume in G1 and proliferation. Biophysical Journal 94: 4984-4995.

47. Natale CF, Ventre M, Netti PA (2014) Tuning the material-cytoskeleton crosstalk via nanoconfinement of focal adhesions. Biomaterials 35: 2743-2751.

48. McKee CT, Raghunathan VK, Nealey PF, Russell P, Murphy CJ (2011) Topographic modulation of the orientation and shape of cell nuclei and their influence on the measured elastic modulus of epithelial cells. Biophys J 101:2139-2146.

49. Wang L, Mercer RR, Rojanasakul Y, Qiu A, Lu Y, et al. (2010) Direct fibrogenic effects of dispersed single-walled carbon nanotubes on human lung fibroblasts. J Toxicol Environ Health A 73:410422.

50. Zaidel-Bar R, Cohen M, Addadi L, Geiger B (2004) Hierarchical assembly of cell-matrix adhesion complexes. Biochem Soc Trans 32: 416-420.

51. Kim DH, Lipke EA, Kim P, Cheong R, Thompson S, et al. (2010) Nanoscale cues regulate the structure and function of macroscopic cardiac tissue constructs. Proc Natl Ac ad Sci U S A 107: 565-570.

52. Jean Ronald P, Gray Darren S, Spector Alexander A, Chen Christopher S (2004) Characterization of the nuclear deformation caused by changes in endothelial cell shape. Journal of biomechanical engineering 126: 552-558.

53. Chen M. et al. Serum Starvation Induced Cell Cycle Synchronization Facilitates Human Somatic Cells Reprogramming. PLoS ONE 7, 1-9 (2012). 


\section{Three-dimensional Microfluidic Co-Culture Model of the Bone Marrow Microenvironment for the Study of Acute Lymphoblastic Leukemia}

\section{Introduction}

\subsection{Physiological Environment}

The bone marrow microenvironment is the primary site of normal hematopoietic cell development as well as the anatomical location in which diverse types of leukemia initiate and progress. It is notably the most frequent site of leukemic relapse, as well as a site of metastasis for many solid tumors including breast, lung, and prostate cancer. Held in common to all tumor cells that either originate or migrate to this site is the propensity to be refractory to treatment [1] thus positioning them to contribute to relapse of disease. As such, it is important to attempt to model this site appropriately to investigate tumor cell survival in this context and to develop drug screens that consider its complexity.

With that goal in mind the current model includes cell types that contribute to the heterogeneity found in this unique space with a focus on an aggressive form of acute lymphoblastic leukemia (ALL) that constitutively expresses the Bcr-Abl fusion protein as a representative model. Bone marrow stromal cells (BMSC) and osteoblasts comprise just two of the well characterized populations that are essential to the developmental support of both normal and leukemic cells in postnatal bone marrow $[2,3]$. These two populations provide secreted cytokines and chemokines as well as support of cell signaling that is prompted through physical interaction of hematopoietic cell surface receptors with adhesion molecules including, but not limited to Vascular Cell Adhesion Molecule-1 (VCAM-1) and fibronectin. The heterogeneity of the supportive microenvironment is significant in terms of cellular constituents but models must also consider extracellular matrix (ECM). Various collagens comprise a significant component of the ECM [4-7] with Collagen I being particularly abundant in the marrow space [8,9]. Of additional influence on hematopoietic cell development is the elasticity of the matrix, which has profound effects on tumorogenesis [10-13]. The interstitial fluid flow in bone, being extremely slow (between 0.1 and $4.0 \mu \mathrm{m} / \mathrm{s}$ [14]), plays an important role in nutrient transport and establishment of the microenvironment $[15,16]$. The interstitial flow has been reported to regulate tumor cell growth, 
differentiation, migration and metastasis [17-21], and to promote angiogenesis and tumorigenic activity of stromal cells [22].

\subsection{Current Tumor Models}

Several models to investigate the influence of the bone marrow microenvironment have been developed that are informative, but continue to rely on combinations of relevant cell types grown in two dimensions (2-D). With recognition of the importance of architecture to the unique anatomy of the bone marrow effort is warranted to improve on these models to attempt to move closer to biological relevance. The 3-D models have been shown to restore cellular morphologies and phenotypes characteristic of in vivo tumor development [23-26]. Simply switching culture dimensionality from 2-D to 3-D drastically affects cell morphology [27], proliferation [28], differentiation [29], gene and protein expression [24,3033], and metabolism [34]. Reflecting the impact of dimensionality, GB1 glioma cells were shown to elongate and flatten in 2-D culture, destroying the typical pseudo-spherical morphology and fillapodial characteristics, but closely resembles the original in vivo phenotype in 3-D culture [35]. Just as cancer cell gene expression patterns can differ, chemotherapy drugs display distinct sensitivities in 2-D versus 3-D $[24,36]$. Two dimensional glioblastoma models were more sensitive to the chemotherapy agent TMZ than 3-D models or the clinical population [35]. Additionally, treatment of MDA-231 3-D cultures, but not MDA-231 monolayers, with the DNA-damaging therapeutic cisplatinum resulted in up-regulation of TGF $\beta 1$ - a response that is predictive of the response in vivo [37]. Three dimensional models also allow investigation of cell-cell interactions [38]. For example, Gao et al. observed the distance dependent effects of soluble factors secreted by L929 fibroblast cells on tumor cell cycle progression in multilayered hydrogels containing living cells [39]. The 3-D matrix model has been further incorporated into microfluidic platforms, thus enabling systematic investigation of both physiological and pathological phenomena in vitro [22,40-47]. In carefully controlled experimental approaches, cancer cell migration $[48,49]$, tumor-stromal cell interactions [50], and tumor-endothelial cell interactions $[41,51]$ have been studied in 3-D microfluidics. For example, breast cancer cells (MDA-MB-231) preferentially migrated along the streamline in a 3-D microfluidic platform, but the direction depended on cell density, CCR7 
receptor activity and interstitial flow velocity [49]. Additionally, extravasation and migration distance of breast cancer cells were signific antly enhanced in a vascularized osteo-cell conditioned microenvironment with human BMSC and endothelial cells [52]. These findings collectively emphasize the value of developing 3-D microfluidic models to interrogate biological questions, including those related to the bone marrow microenvironment, as the focus of the current work. 


\section{Objective}

The objective of this project was to investigate the influence of the bone marrow microenvironment on the chemoresistance of aggressive leukemic cells for Acute Lymphoblastic Leukemia (ALL). In our study, we co-cultured three biologically relevant populations of bone marrow niche cell types: bone marrow stromal cells, human osteoblasts, and an aggressive leukemic cell line. The study compared traditional 2-D static tumor alone and co-culture models to 3-D static and 3-D dynamic models. By creating this model, we set out to establish an in vitro model which addresses in vivo characteristics, such as, dimensionality, cell-cell interactions, and interstitial fluid flow. By incorporating these crucial features, we hoped to create a model which better mimics the in vivo scenario, therefore, contributing to cancer progression and treatment analysis. 


\section{Materials and Methods}

\subsection{Fabrication of a Microfluidic Platform}

The microchannels of $500 \mu \mathrm{m}$ width, $75 \mu \mathrm{m}$ height and $2 \mathrm{~cm}$ length were generated via conventional photolithography [53]. The micropattern created with AutoCAD was printed on a transparency film that served as the photomask and SU-8 2050 (MicroChem Corp., Newton, MA, USA) was used as the substrate.

Polydimethylsiloxane (PDMS) resin and curing agent (Sylgard 184 kit, Dow Corning, MI, USA) was mixed at a 10:1.05 w/w ratio and poured over the SU-8 mold. After curing at $70^{\circ} \mathrm{C}$ for $2 \mathrm{hr}$, the inverse PDMS mold was peeled from the SU-8 mold.

The microfluidic platforms were assembled in two manners, conventional oxygen plasma assembly and novel microtransfer assembly as described previously [54]. Oxygen plasma provided a permanent assembly while microtransfer assembly was reversible. Briefly, the PDMS mold with microchannels and the glass coverslip were exposed to oxygen plasma at $300 \mathrm{mTorr}(40 \mathrm{~Pa}), 50$ watt for $15 \mathrm{~s}$ in a March PX250 Plasma Asher from Nordson Co. (Westlake, OH, USA). The oxidized PDMS microchannels and glass coverslip were brought into contact and then placed in an oven at $125^{\circ} \mathrm{C}$ for $15 \mathrm{~min}$ to complete the assembly. During microtransfer assembly, 5 wt.\% PDMS prepolymer in hexane solution was spin-coated onto a Si wafer to form a thin film, which served as an adhesive layer to assemble PDMS microchannels onto a glass coverslip. The coverslip was pretreated with oxygen plasma as described above. The assembly was post-cured at $80^{\circ} \mathrm{C}$ for $2 \mathrm{hr}$. The microtransfered assembly allowed to peel the PDMS mold off from the coverslip after cell studies and thus the cell-encapsulated hydrogel matrix could be retrieved for analysis.

Prior to cellular studies, the platform was sterilized by injecting and retaining $70 \%$ ethanol within the microchannels for $15 \mathrm{~min}$ followed by UV exposure for $15 \mathrm{~min}$.

\subsection{Cell Culture}

Human bone marrow stromal cell (BMSC) cultures were initiated from human bone marrow from consenting donors, with approval by the West Virginia University Institutional Review Board. All 
primary BMSC cultures were initiated from donors with no previous chemotherapy exposure. BMSC were maintained in $\alpha$-modification of Eagle's medium ( $\alpha$-MEM; Gibco, Grand Island, NY, USA) supplemented with 10\% fetal bovine serum (Hyclone, Logan, UT, USA), 1\% L-glutamine (Gibco), 1\% penicillin/streptomycin (Sigma, St. Louis, MO, USA), and 0.1\% 2- $\beta-$ mercaptoethanol (Sigma). Human osteoblasts (HOB) were purchased from Promocell (Heidelberg, Germany) and maintained in osteoblast growth media. The human Philadelphia chromosome positive $(\mathrm{Ph}+) \mathrm{B}$ lineage ALL cell line SUP-B15 (CRL-1929) was obtained from ATCC and cultured in Iscove's DMEM (Mediatech, Manassas, VA, USA) supplemented with $10 \%$ fetal bovine serum, $2 \mathrm{mML}$-glutamine, $0.05 \mu \mathrm{M} 2-\beta-$ mercaptoethanol and $1 \%$ penicillin/streptomycin.

\subsection{Tumor Models}

Two groups of culture conditions were compared that included SUP-B15 leukemic cells alone or SUP-B15 cells co-cultured with $\mathrm{HOB}$ or BMSC. The total cell density was maintained at $20 \times 10^{6}$ cells/mL. In co-culture experiments, SUP-B15 cells were mixed at a 10:2:2 ratio with HOB and BMSC. The cells were resuspended in $100 \mu \mathrm{L}$ complete culture medium, gently mixed with of $10 \% 10 \mathrm{X}$ PBS, $2 \%$ $\mathrm{NaOH}$, and $88 \%$ Collagen I (rat-tail, BD Biosciences, Franklin Lakes, NJ, USA), and then injected into the microfluidic platform previously described. The platform was incubated at $37^{\circ} \mathrm{C}$ for $1 \mathrm{hr}$ to allow collagen I to gelate before the culture media was continuously pumped through the platform at a flow rate of $800 \mu \mathrm{L}$ per day using a Harvard Apparatus PhD Ultra Pump (Harvard Apparatus, Holliston, MA, USA) to sustain cell culture for a predefined period of time. For comparison, both tumor cells alone (SUP-B15 only) and co-culture with BMSC and $\mathrm{HOB}$ were studied in 2-D and 3-D configurations under the static condition. In the 2-D static model, cells were seeded in 6-well tissue culture polystyrene (TCPS) plates. In the 3-D static model, the mixture of cells (SUP-B15 + BMSC + HOB) with collagen I was plated in 24well culture plates and allowed to gelate.

To demonstrate cell-cell interactions in 3-D matrices, SUP-B15 leukemic cells, BMSC and HOB were fluorescently labeled by using Cell Tracker Green CMFDA, Red CMTPX, and far red shown in blue, respectively. The Cell Trackers were obtained from Life Technologies, Grand Island, NY, USA. 


\subsection{Chemotherape utic Reagents and Treatment}

Antimetabolite chemotherapeutic drug, Ara-C (Sigma) was used to evaluate therapeutic effects on tumor cells. Ara-C was stored at $-80^{\circ} \mathrm{C}$ at $10 \mathrm{mg} / \mathrm{mL}$, and diluted in the base media used for leukemic cell culture immediately before use. After $72 \mathrm{~h}$ incubation, tumor cells cultured in 2-D and 3-D under static conditions were treated with $1 \mu \mathrm{M}$ Ara-C for $48 \mathrm{hr}$ to best mimic an ALL patient's drug serum concentration during treatment, while 3-D dynamic platforms were exposed to continuous flow of $1 \mu \mathrm{M}$ Ara-C in complete culture media for $48 \mathrm{hr}$. Viability was evaluated by both flow cytometry and immunofluorescence image analysis.

\subsection{Flow Cytometry}

Collection of tumor cells from 3-D matrices was accomplished by incubation of cultures in type I collagenase (Life Technologies). The collagenase was used to digest collagen I in the 3-D static model according to the manufacture protocol. Apoptotic cells were detected by staining with Annexin V-Alexa 555 assay (Life Technologies) and gated against cells stained with CellTracker ${ }^{\mathrm{TM}}$ Green CMFDA. Data were acquired using a FACSFortessa flow cytometer with Cell Quest Pro software (BD Biosciences, Franklin Lakes, NJ, USA). Experiments were repeated in triplicate.

\subsection{Immunofluorescnece Staining}

Annexin V Staining. Apoptotic cells were detected by staining with Annexin V-Alexa 555 (1:50) assay. Three-dimensional static and dynamic cell-matrix samples were washed with PBS and then stained with Annexin V overnight at $4^{\circ} \mathrm{C}$. Samples were washed, fixed with $1 \%$ parafomaldahyde (PFA), and imaged on the same day. After immunofluorescence staining, cells were imaged using a Zeiss LSM 510 confocal microscope.

\subsection{Confocal Image Analysis Using Imaris}

Immunofluorescence images were analyzed using Imaris software (Bitplane, Windsor, CT, USA). The surface function was used to reconstruct objects in the FITC (green) and TRITC (red) channels. First, the threshold was adjusted to a level where the superimposed confocal image matched that of the created objects. The objects created were then filtered based on size to remove unwanted noise and to evaluate 
only tumor cell viability. Remaining objects were counted based on color. Red Annexin V-positive cells were counted as not viable, while green Annexin V-negative cells were counted as viable.

\subsection{Statistical Analysis}

Viability percentages were expressed as mean \pm standard error from three independent experiments. Immunostained images of no less than 10,000 tumor cells/sample for the 2-D model and 200 tumor cells/sample for the 3-D models were evaluated. The differences between groups were analyzed by oneway ANOVA and Tukey's method for multiple comparisons. $\mathrm{p}<0.10$ was taken as statistically significant for tumor alone and co-culture comparison and $\mathrm{p}<0.05 \mathrm{w}$ as taken as statistically significant for 2-D and 3-D comparison. 


\section{Results and Discussion}

\subsection{Essential Elements in Tumor Models}

The current study sought to develop a 3-D model with utility for investigation of tumor cell biology in the context of the bone marrow microenvironment as the site of initiation of leukemic disease and as the frequent site of metastatic malignancies characterized by therapeutic resistance. Inherent to this design were considerations of interstitial flow, dimensionality and cell-cell interactions (Figure 2.1) as critical parameters that impact on cell morphology and signaling that impacts on critical downstream pathways. BMSC and HOB were included as representative, but not exclusive, elements of the bone marrow microenvironment that have been well documented to influence both normal hematopoietic cell development as well as impacting on tumor cell quiescence, proliferation, and survival in this unique anatomical niche $[8,9]$. Collagen I was chosen for inclusion based on its predominance in the bone marrow, however, it was recognized that the extracellular matrix required to generate a truly biologically representative model would be more complex and include several types of collagens, hyaluronate, and fibronectin as well as other structural components $[8,55,56]$.

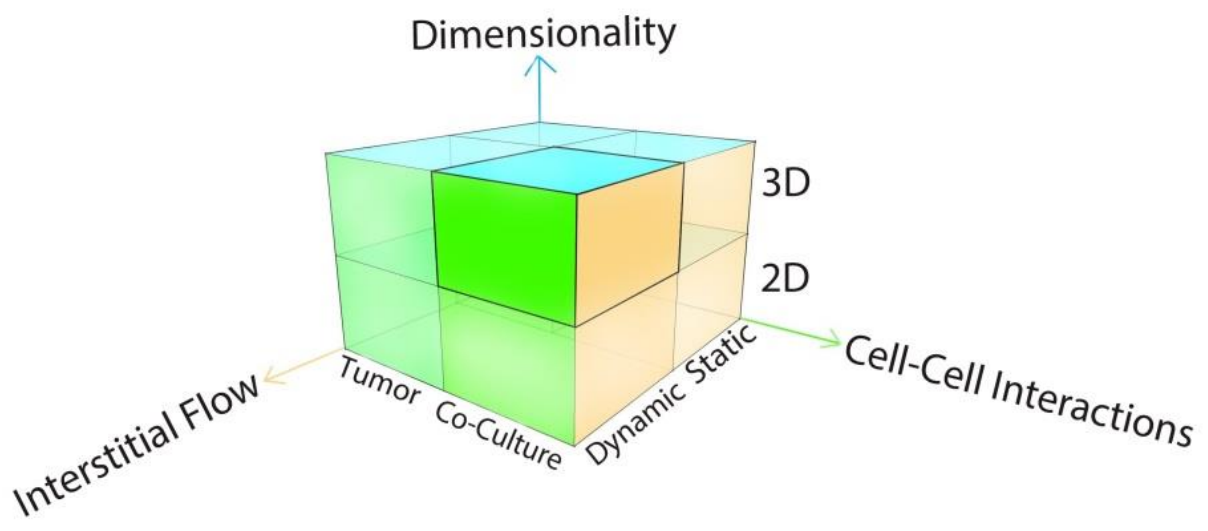

Figure 2.1: Schematic illustration of tumor models. The three factors tested in this study include dimensionality, cell-cell interactions and interstitial flow. 


\subsection{Microfluidic Design and Fabrication}

A typical 3-D microfluidic platform was shown in Fig. 2.2. Tumor cells alone or co-culture with BMSC and HOB mixed with Collagen I were injected through the "Cells In" inlet into four microchannels, which were $500 \mu \mathrm{m}$ in width, $75 \mu \mathrm{m}$ in height and $2 \mathrm{~cm}$ in length. After Collagen I gelated at $37^{\circ} \mathrm{C}$ incubator for $1 \mathrm{hr}$, the culture medium was flowed through a "Media In" inlet into the four microchannels for a predefined period of time (Fig. 2.2B). Near the inlet and outlet, perfusion channels comprising of four rows of $100 \mu \mathrm{m}$ X $100 \mu \mathrm{m}$ columns with a spacing of $80 \mu \mathrm{m}$ were fabricated to help retain the cells within the main microchannels (Fig. 2.2C). The velocity profile within the microchannels deviated from Poiseuille flow because the compliant collagen hydrogel, the various pore size and cellinduced matrix remodeling. important [22]. By tracking the movement of injected TRITC-labelled beads, the velocity was determined to be $2.3 \mu \mathrm{m} / \mathrm{s}$, which was within the physiological range.
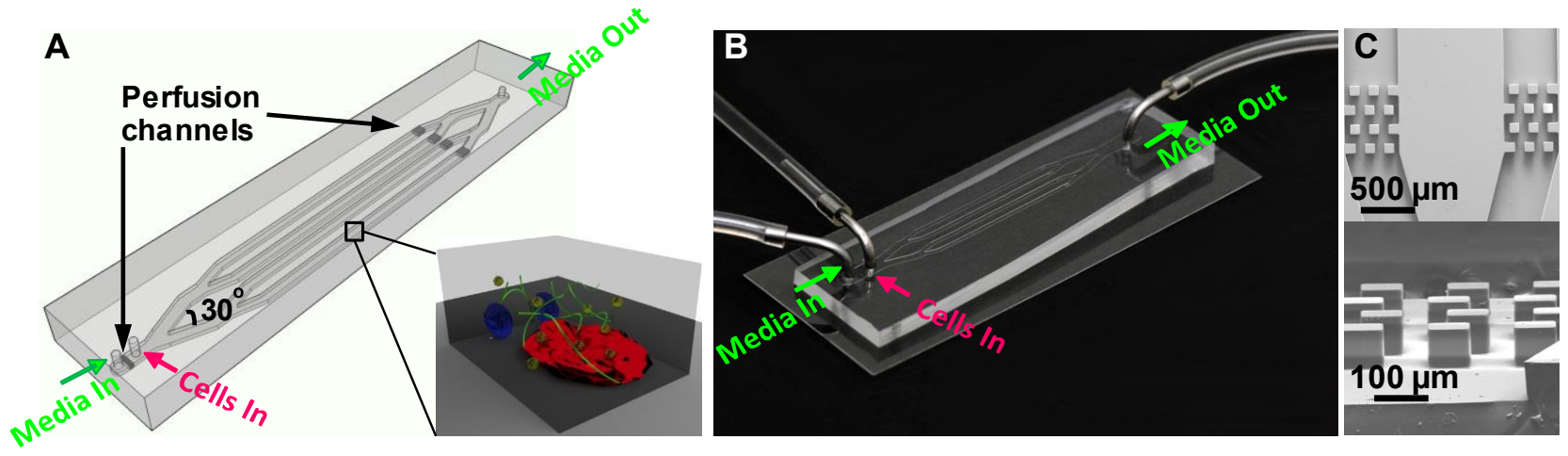

Figure 2.2: A typical 3-D microfluidic co-culture model. (A) The microfluidic platform consists of 4 microchannels, each $500 \mu \mathrm{m}$ in width, $75 \mu \mathrm{m}$ in height and $2 \mathrm{~cm}$ in length. The divergent angles are $30^{\circ}$. Near the inlets and outlet there are perfusion channels. The enlarged boxed area illustrates multiple cell types embedded in a 3-D matrix. (B) Optical image of the microfluidic platform. (C) SEM images of top view (upper panel) and side view (lower panel) of the perfusion channels. 


\subsection{Co-Culture Models}

Confocal and Imaris generated reconstruction images (Figure 2.3) show that in both 2-D and 3-D

static as well as in 3-D dynamic experimental circumstances all cell populations can be readily discerned with 3-D reconstruction demonstrating direct cell-cell interactions with HOB and BMSC. Cross sections (CS) (Figure 2.3A) demonstrate the compaction of the 2-D static model compared to the 3-D circumstance in which the dimensionality can be appreciated. The cell-cell interactions are further emphasized in Fig. 2.3B upon rotation of the 3-D reconstruction images around the $\mathrm{X}$ and $\mathrm{Y}$ axis indicating tumor cell interaction with structural cells (BMSC and HOB). 
A

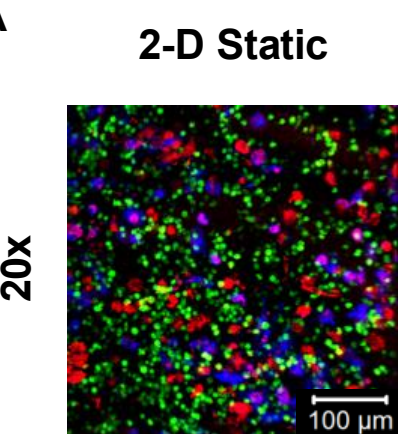

3-D Static 3-D Dynamic
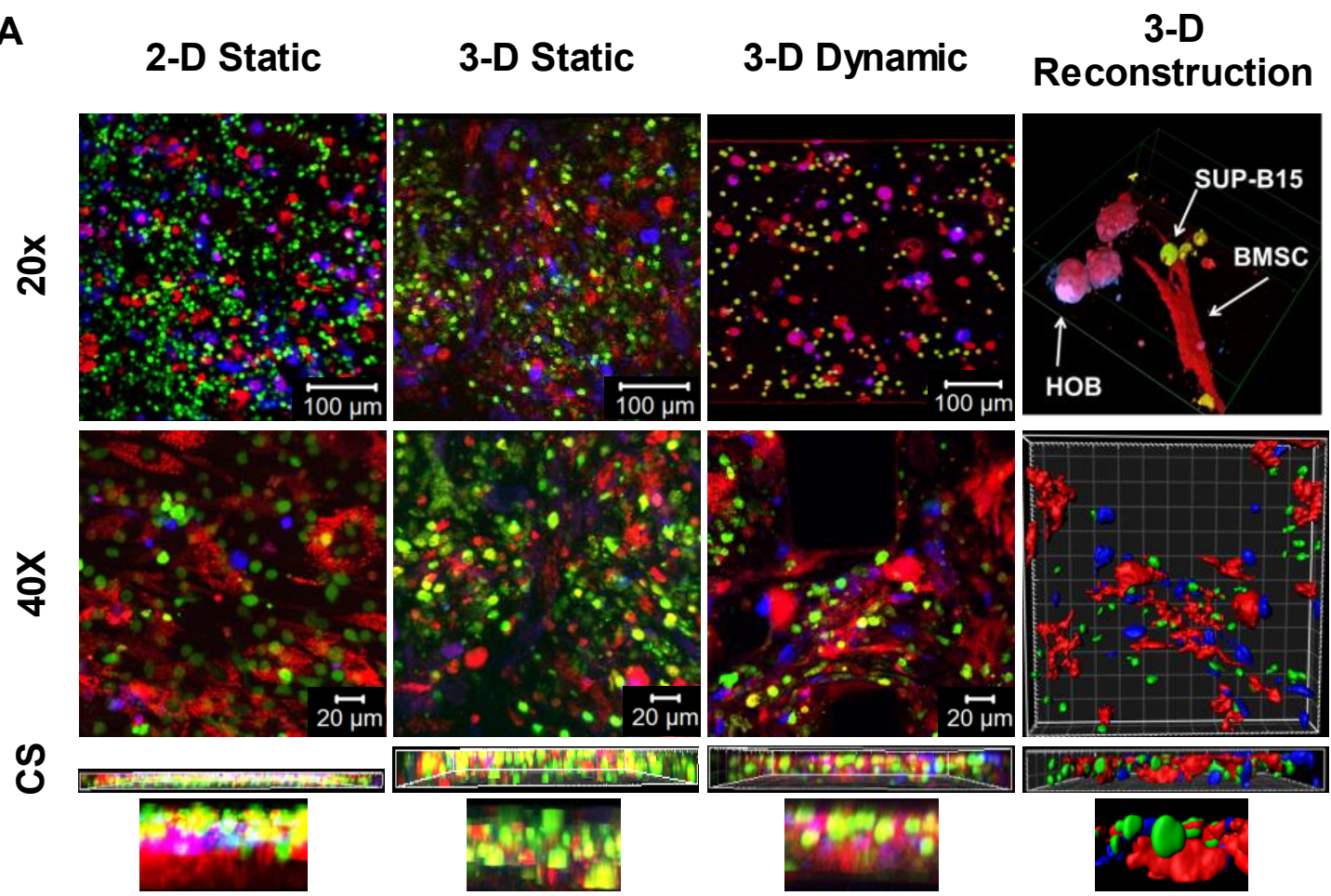

B
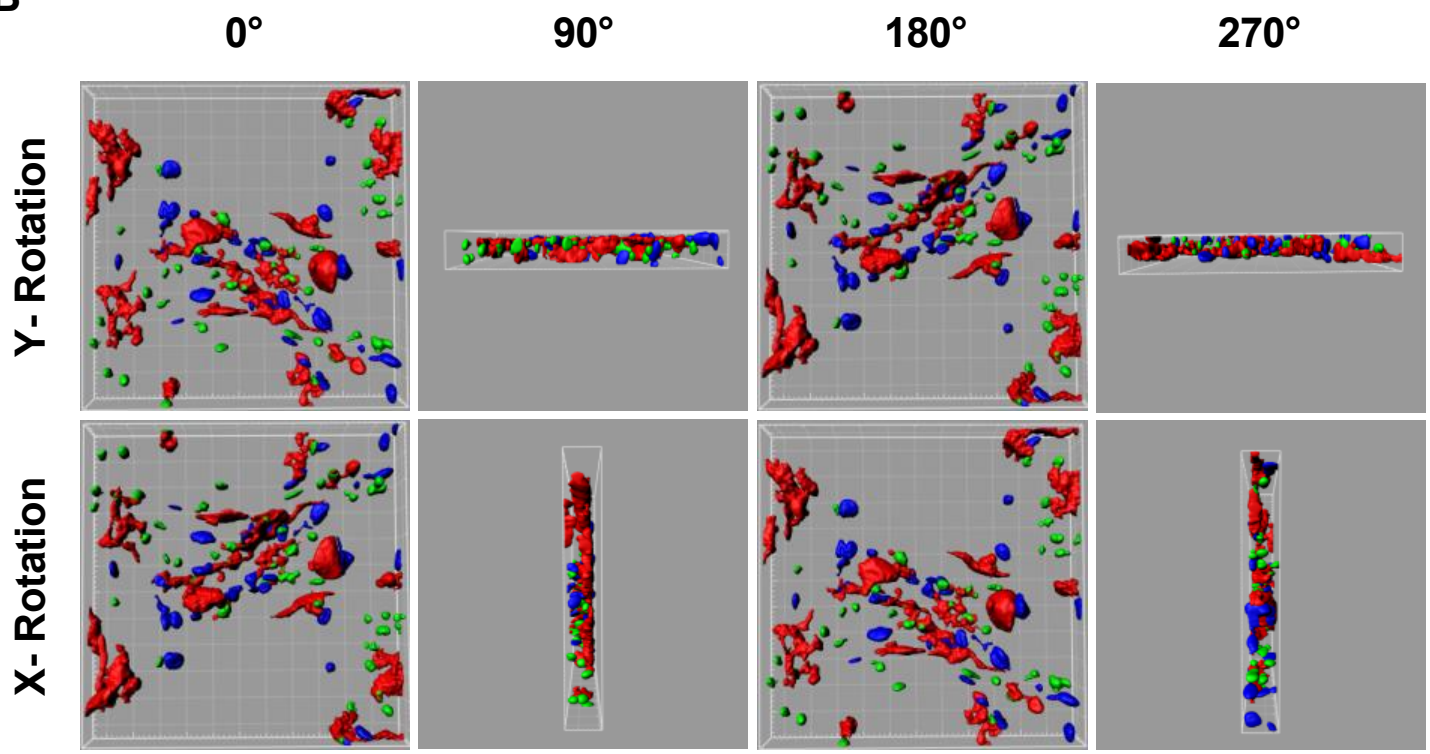

Figure 2.3: Representative tumor models. (A) Confocal and Imaris reconstruction images of the tumor models at low magnification (20X), high magnification (40X) and high magnification cross sections (CS). The cell-cell interactions in z-direction in the boxed region of CS images are enlarged in Row 4. The heights for 2-D and 3D CS images are $10 \mu \mathrm{m}$ and $30 \mu \mathrm{m}$, respectively. (B) 3-D reconstruction images rotated via $x^{-}$and $y$-axis revealing cell-cell interactions. 


\subsection{Drug Sensitivity across Platforms}

It has been reported that both stromal cells and osteoblasts enhance leukemic cell survival during chemotherapy exposure with previous experiments typically completed in traditional 2-D cultures $[57,58]$. The relevance of this observation is that surviving tumor cells in the context of leukemia directly correlate with the likelihood of relapse of disease [59] and as such more biologically relevant models to interrogate the protective effect of critical elements of the microenvironment are warranted. In the current study, we determined that this trend of microenvironment protection of tumor cells grown with access to BMSC or HOB was also observed in both 3-D static and 3-D dynamic (microfluidic) models. Flow cytometry and confocal microscopy were used to evaluate viability of tumor cells in the 2-D and 3D models (Fig. 2.4). Regardless of whether the 3-D configuration was static or had a steady media flow during culture, it was associated with significantly higher survival of tumor cells during Ara-C exposure as well as enhanced protection during chemotherapy stress conferred by microenvironment cells (Fig. 2.5, 2.6). 

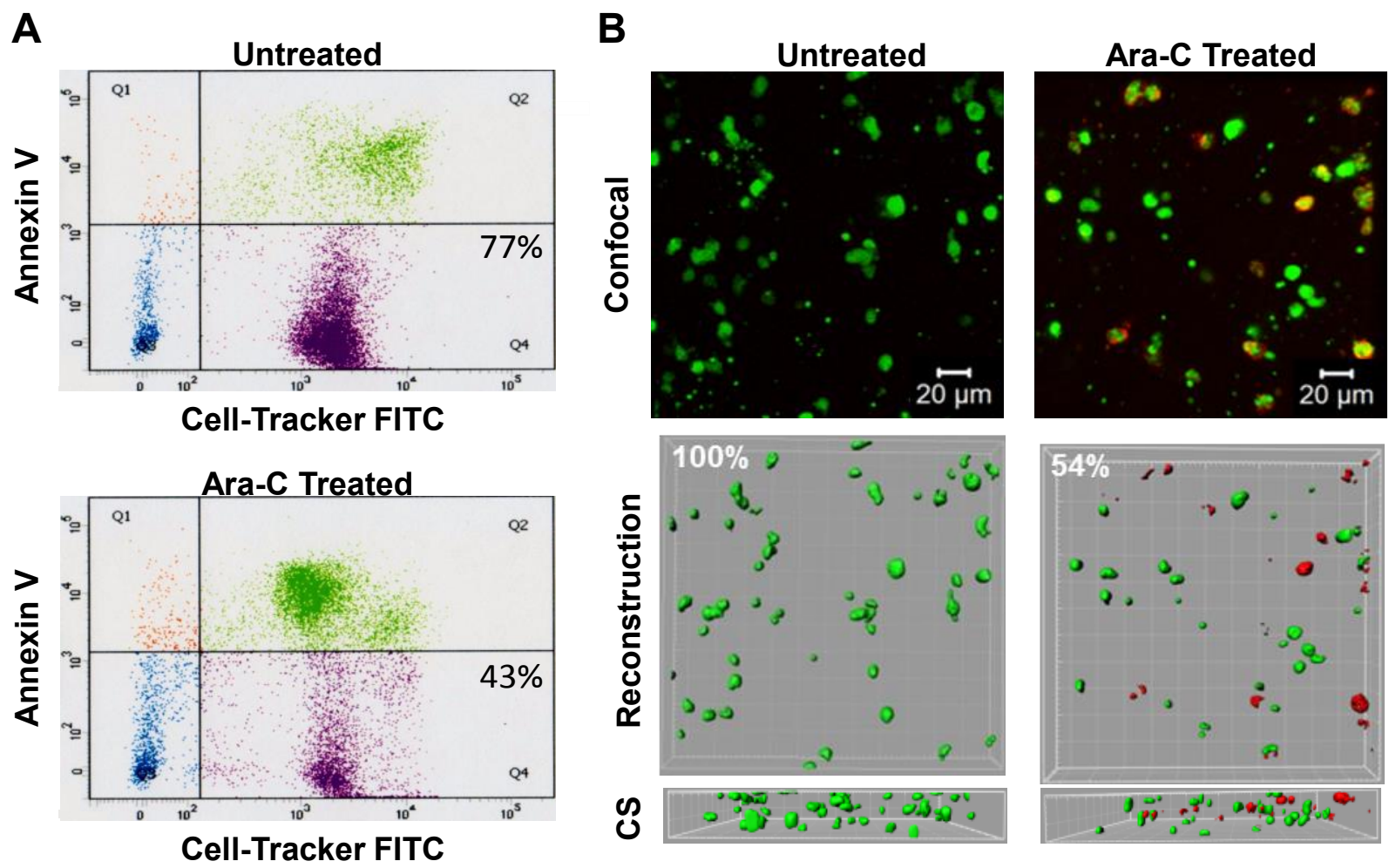

Figure 2.4: (A) Typical flow cytometry analysis for untreated 2-D tumor model (left) and Ara-C treated 3-D co-culture model (right) using collagenase to digest collagen matrix. (B) Typical immunofluorescence image analysis of untreated (left) and treated (right) 3-D dynamic tumor models. 


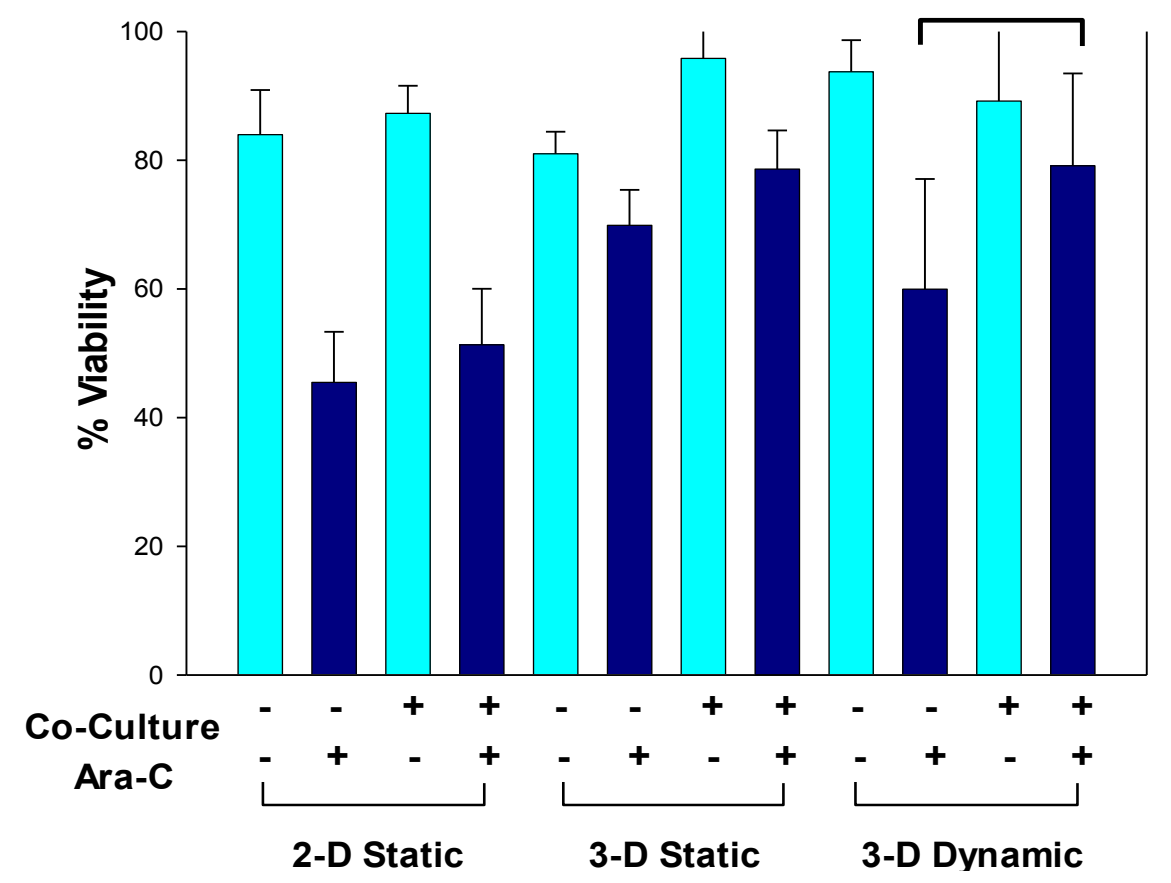

Figure 2.5. Comparison in chemoresistance of tumor cells to Ara-C among a variety of tumor models. (A) The effects of dimensionality, co-culture and interstitial flow on the viability of tumor cells. Bracket shows significant $(\mathrm{p}<0.1)$ difference between treated tumor and treated co-culture.

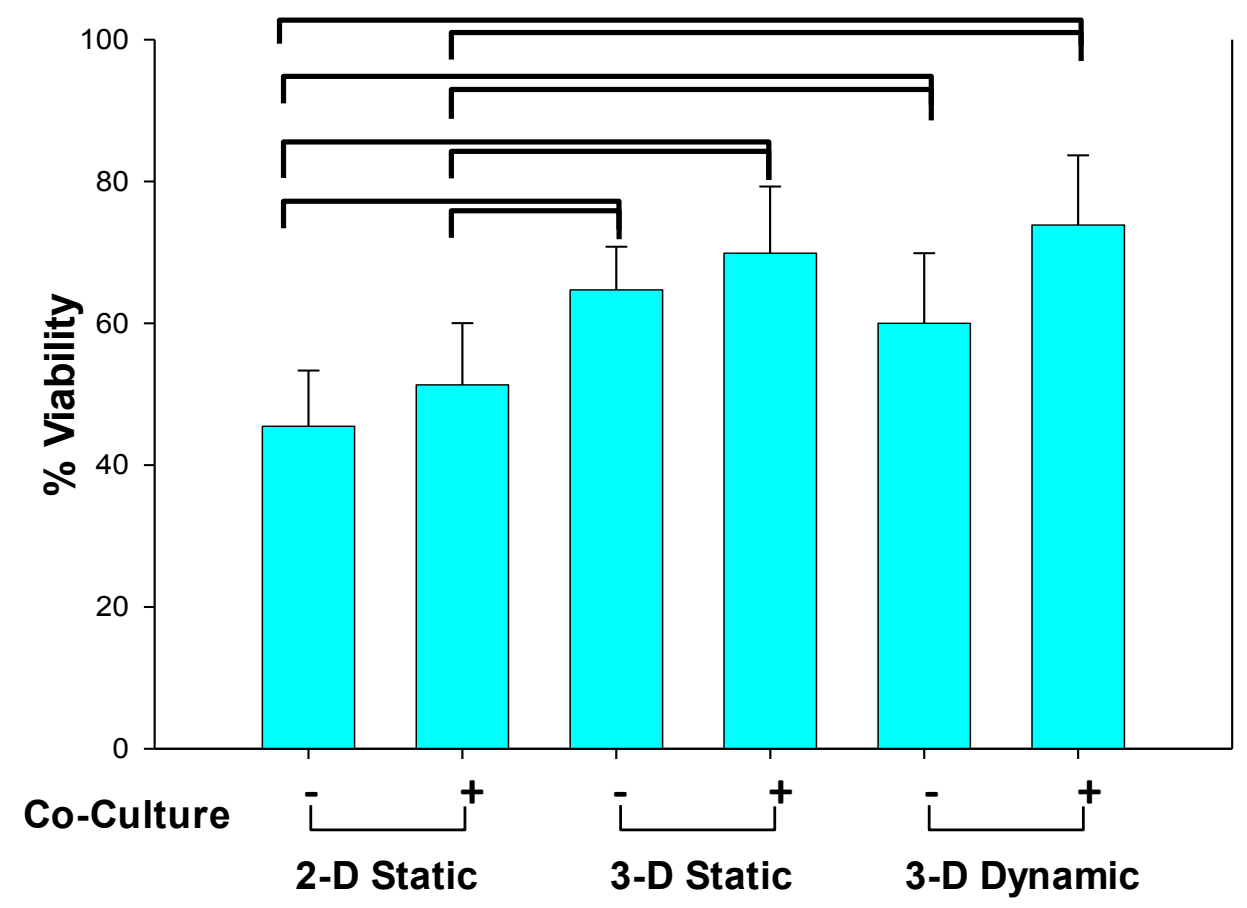

Figure 2.6: The effects of 3-D culture on tumor cell viability under the co-culture condition. Brackets reveal significant $(\mathrm{p}<0.05)$ difference in 3-D and 2-D models. All 3-D models showed significant difference when compared to 2-D models. 
The observed chemoresistance difference in 3-D culture can be attributed to the enhanced cell-matrix interactions. Over the past decade, a growing number of reports have shown that there are different signaling mechanisms in 3-D microenvironments compared to 2-D substrates [60,61]. Moreover, tumor cells cultured in three dimensions have been shown to be less sensitive to apoptosis induced by radiochemo treatments or by death receptor ligation compared to cells cultured in two dimensions [62]. Cytotoxic effects of chemotherapeutic agents have also been shown to be significantly reduced in cells cultured in three dimensions $[24,63,64]$. These data suggest that investigation of leukemic cell protection by bone marrow microenvironment cues in traditional 2-D culture models can provide meaningful information in which trends are confirmed in 3-D culture, but that more accurate measures of the magnitude of effect may require further development of 3-D models. No readouts were observed that were not consistent between 2-D and 3-D based experiments, and as such, practical downstream evaluation of cells may also drive the experimental design choice. Potentially experiments in which large numbers of tumor cells are required for recovery at the cessation of cytotoxic exposure may be best aligned with 2-D approaches, with 3-D lending itself best to single cell analyses or polymerase chain reaction (PCR) based applications. We have documented that leukemic cells can be recovered via collagenase digestion and cell sorting with high quality RNA that is appropriate for RT-PCR being easily recovered. This will broaden the realm of experiments that will be possible related to gene expression studies in this microenvironment model. 


\section{Conclusion}

Relapse of leukemic disease in high risk categories of ALL remains a significant clinical challenge, with pre-clinical models providing platforms for investigation of pathways that influence tumor cell quiescence, the regulation of tumor stem cell phenotype, and modulation of apoptotic pathways as just a few of the elements that converge on response to therapy. In combination with appropriate in vivo models, it remains essential to optimize in vitro models to more accurately mimic the complexity of the bone marrow microenvironment to provide new tools for investigation of the mechanisms that underpin survival of residual disease and relapse. The microfluidics model in the current study represents one step in this effort with relevance to both leukemic disease as well as metastasis of solid tumors to the bone marrow where they also benefit from the protective niche during therapy.

The current study showed decreased chemotherapeutic drug sensitivity of leukemic cells when cocultured with BMSC and HOB and exposed to flow. The engineered 3-D microfluidic co-culture model allowed precise control over the mechanical properties of matrix and fluidic shear stress and enabled systematic investigation of effects of cell-cell and cell-matrix interactions on cancer initiation and progression, thus improving our limited comprehension of the role of microenvironmental signals in cancer biology. 


\section{References}

1. Infanger DW, Lynch ME, Fischbach C (2013) Engineered culture models for studies of tumormicroenvironment interactions. Annu Rev Biomed Eng 15: 29-53.

2. Calvi LM, Adams GB, Weibrecht KW, Weber JM, Olson DP, et al. (2003) Osteoblastic cells regulate the haematopoietic stem cell niche. Nature 425: 841-846.

3. Mayani H, Guilbert LJ, Janowska-Wieczorek A (1992) Biology of the hemopoietic microenvironment. European Journal of Haematology 49: 225-233.

4. Gordon MY (1988) Extracellular Matrix of the Marrow Microenvironment. British Journal of Haematology 70: 1-4.

5. Klein G (1995) The extrac ellular matrix of the hematopoietic microenvironment. Experientia 51: 914926.

6. Gronthos S, Simmons PJ, Graves SE, Robey PG (2001) Integrin-mediated interactions between human bone marrow stromal precursor cells and the extracellular matrix. Bone 28: 174-181.

7. Chen XD, Dusevich V, Feng JQ, Manolagas SC, Jilka RL (2007) Extrac ellular matrix made by bone marrow cells facilitates expansion of marrow-derived mesenchymal progenitor cells and prevents their differentiation into osteoblasts. J Bone Miner Res 22: 1943-1956.

8. Shi S, Kirk M, Kahn AJ (1996) The role of type I collagen in the regulation of the osteoblast phenotype. J Bone Miner Res 11: 1139-1145.

9. Hamilton R, Campbell FR (1991) Immunochemical localization of extracellular materials in bone marrow of rats. The Anatomical Record 231:218-224.

10. Gurkan U, Akkus O (2008) The Mechanical Environment of Bone Marrow: A Review. Annals of Biomedical Engineering 36: 1978-1991.

11. Paszek MJ, Zahir N, Johnson KR, Lakins JN, Rozenberg GI, et al. (2005) Tensional homeostasis and the malignant phenotype. Cancer Cell 8: 241-254.

12. Holst J, Watson S, Lord MS, Eamegdool SS, Bax DV, et al. (2010) Substrate elasticity provides mechanical signals for the expansion of hemopoietic stem and progenitor cells. Nat Biotech 28: $1123-1128$.

13. Liu J, Tan Y, Zhang H, Zhang Y, Xu P, et al. (2012) Soft fibrin gels promote selection and growth of tumorigenic cells. Nat Mater 11:734-741.

14. Dafni H, Israely T, Bhujwalla ZM, Benjamin LE, Neeman M (2002) Overexpression of vascular endothelial growth factor 165 drives peritumor interstitial convection and induces lymphatic drain: magnetic resonance imaging, confocal microscopy, and histological tracking of triplelabeled albumin. Cancer Research 62: 6731-6739.

15. Rutkowski JM, Swartz MA (2007) A driving force for change: Interstitial flow as a morphoregulator. Trends in Cell Biology 17: 44-50.

16. Hillsley MV, Frangos JA (1994) Bone tissue engineering: the role of interstitial fluid flow. Biotechnology and Bioengineering 43: 573-581. 
17. Chang SF, Chang CA, Lee DY, Lee PL, Yeh YM, et al. (2008) Tumor cell cycle arrest induced by shear stress: Roles of integrins and Smad. Proc Natl Acad Sci U S A 105: 3927-3932.

18. Shieh AC, Swartz MA (2011) Regulation of tumor invasion by interstitial fluid flow. Phys Biol 8: 015012 .

19. Shieh AC, Rozansky HA, Hinz B, Swartz MA (2011) Tumor cell invasion is promoted by interstitial flow-induced matrix priming by stromal fibroblasts. Cancer Res 71: 790-800.

20. Hompland T, Ellingsen C, Ovrebo KM, Rofstad EK (2012) Interstitial fluid pressure and associated lymph node metastasis revealed in tumors by dynamic contrast-enhanced MRI. Cancer Res 72: 4899-4908.

21. Haessler U, Teo JC, Foretay D, Renaud P, Swartz MA (2012) Migration dynamics of breast cancer cells in a tunable 3D interstitial flow chamber. Integr Biol (Camb) 4: 401-409.

22. Buchanan CF, Voigt EE, Szot CS, Freeman JW, Vlachos PP, et al. (2014) Three-dimensional microfluidic collagen hydrogels for investigating flow-mediated tumor-endothelial signaling and vascular organization. Tissue Eng Part C Methods 20: 64-75.

23. Yamada KM, Cukierman E (2007) Modeling tissue morphogenesis and cancer in 3D. Cell 130: 601610.

24. Fischbach C, Chen R, Matsumoto T, Schmelzle T, Brugge JS, et al. (2007) Engineering tumors with 3D scaffolds. Nat Methods 4: 855-860.

25. Cross VL, Zheng Y, Won Choi N, Verbridge SS, Sutermaster BA, et al. (2010) Dense type I collagen matric es that support cellular remodeling and microfabrication for studies of tumor angiogenesis and vasculogenesis in vitro. Biomaterials 31: 8596-8607.

26. Szot CS, Buchanan CF, Freeman JW, Rylander MN (2011) 3D in vitro bioengineered tumors based on collagen I hydrogels. Biomaterials 32: 7905-7912.

27. Cukierman E, Pankov R, Stevens DR, Yamada KM (2001) Taking cell-matrix adhesions to the third dimension. Science 294: 1708-1712.

28. Wang F, Weaver VM, Petersen OW, Larabell CA, Dedhar S, et al. (1998) Reciprocal interactions between beta1-integrin and epidermal growth factor receptor in three-dimensional basement membrane breast cultures: a different perspective in epithelial biology. Proc Natl Acad Sci U S A 95: 14821-14826.

29. Huebsch N, Arany PR, Mao AS, Shvartsman D, Ali OA, et al. (2010) Harnessing traction-mediated manipulation of the cell/matrix interface to control stem-cell fate. Nature Materials 9: 518-526.

30. Kiss DL, Windus LC, Avery VM (2013) Chemokine receptor expression on integrin-mediated stellate projections of prostate cancer cells in 3D culture. Cytokine 64: 122-130.

31. Windus LC, Kiss DL, Glover T, Avery VM (2012) In vivo biomarker expression patterns are preserved in 3D cultures of Prostate Cancer. Exp Cell Res 318: 2507-2519.

32. Fischbach C, Kong HJ, Hsiong SX, Evangelista MB, Yuen W, et al. (2009) Cancer cell angiogenic capability is regulated by $3 \mathrm{D}$ culture and integrin engagement. Proc Natl Acad Sci U S A 106: 399-404. 
33. Kenny PA, Lee GY, Myers CA, Neve RM, Semeiks JR, et al. (2007) The morphologies of breast cancer cell lines in three-dimensional assays correlate with their profiles of gene expression. Mol Oncol 1: 84-96.

34. Rhodes NP, Srivastava JK, Smith RF, Longinotti C (2004) Metabolic and histological analysis of mesenchymal stem cells grown in 3-D hyaluronan-based scaffolds. J Mater Sci Mater Med 15: 391-395.

35. Jiguet Jiglaire C, Baeza-Kallee N, Denicolai E, Barets D, Metellus P, et al. (2013) Ex vivo cultures of glioblastoma in three-dimensional hydrogel maintain the original tumor grow th behavior and are suitable for preclinical drug and radiation sensitivity screening. Exp Cell Res.

36. Aljitawi OS, Li D, Xiao Y, Zhang D, Ramachandran K, et al. (2014) A novel three-dimensional stromal-based model for in vitro chemotherapy sensitivity testing of leukemia cells. Leuk Lymphoma 55: 378-391.

37. Ohmori T, Yang JL, Price JO, Arteaga CL (1998) Blockade of tumor cell transforming growth factorbetas enhances cell cycle progression and sensitizes human breast carcinoma cells to cytotoxic chemotherapy. Exp Cell Res 245: 350-359.

38. Sung KE, Su X, Berthier E, Pehlke C, Friedl A, et al. (2013) Understanding the impact of 2D and 3D fibroblast cultures on in vitro breast cancer models. PLoS One 8: e76373.

39. Gao B, Konno T, Ishihara K (2014) Quantitating distance-dependent, indirect cell-cell interactions with a multilayered phospholipid polymer hydrogel. Biomaterials 35: 2181-2187.

40. Song JW, Bazou D, Munn LL (2012) Anastomosis of endothelial sprouts forms new vessels in a tissue analogue of angiogenesis. Integr Biol (Camb) 4: 857-862.

41. Zervantonakis IK, Hughes-Alford SK, Charest JL, Condeelis JS, Gertler FB, et al. (2012) Threedimensional microfluidic model for tumor cell intravasation and endothelial barrier function. Proc Natl Acad Sci U S A 109: 13515-13520.

42. Zheng Y, Chen J, Craven M, Choi NW, Totorica S, et al. (2012) In vitro microvessels for the study of angiogenesis and thrombosis. Proc Natl Acad Sci U S A 109: 9342-9347.

43. Ling Y, Rubin J, Deng Y, Huang C, Demirci U, et al. (2007) A cell-laden microfluidic hydrogel. Lab Chip 7: 756-762.

44. Lee KH, Kwon GH, Shin SJ, Baek JY, Han DK, et al. (2009) Hydrophilic electrospun polyurethane nanofiber matrices for hMSC culture in a microfluidic cell chip. J Biomed Mater Res A 90: 619628.

45. Toh YC, Ng S, Khong YM, Samper V, Yu H (2005) A configurable three-dimensional microenvironment in a microfluidic channel for primary hepatocyte culture. Assay Drug Dev Technol 3: 169-176.

46. Cheng SY, Heilman S, Wasserman M, Archer S, Shuler ML, et al. (2007) A hydrogel-based microfluidic device for the studies of directed cell migration. Lab Chip 7: 763-769.

47. Lee KH, Lee KH, Lee J, Choi H, Lee D, et al. (2013) Integration of microfluidic chip with biomimetic hydrogel for $3 \mathrm{D}$ controlling and monitoring of cell alignment and migration. J Biomed Mater Res A. 
48. Abhyankar VV, Toepke MW, Cortesio CL, Lokuta MA, Huttenlocher A, et al. (2008) A platform for assessing chemotactic migration within a spatiotemporally defined 3D microenvironment. Lab Chip 8: 1507-1515.

49. Polacheck WJ, Charest JL, Kamm RD (2011) Interstitial flow influences direction of tumor cell migration through competing mechanisms. Proc Natl Acad Sci U S A 108: 11115-11120.

50. Huang CP, Lu J, Seon H, Lee AP, Flanagan LA, et al. (2009) Engineering microscale cellular niches for three-dimensional multic ellular co-cultures. Lab Chip 9: 1740-1748.

51. Song JW, Cavnar SP, Walker AC, Luker KE, Gupta M, et al. (2009) Microfluidic endothelium for studying the intravascular adhesion of metastatic breast cancer cells. PLoS One 4: e5756.

52. Bersini S, Jeon JS, Dubini G, Arrigoni C, Chung S, et al. (2014) A microfluidic 3D in vitro model for specificity of breast cancer metastasis to bone. Biomaterials 35: 2454-2461.

53. Yang Y, Basu S, Tomasko DL, Lee LJ, Yang S-T (2005) Fabrication of well-defined PLGA scaffolds using novel micro-embossing and carbon dioxide bonding. Biomaterials 26: 2585-2594.

54. Yang Y, Kulangara K, Sia J, Wang L, Leong K (2011) Engineering of a microfluidic cell culture platform embedded with nanoscale features. Lab on a Chip 11: 1638-1646.

55. Zuckerman KS, Wicha MS (1983) Extracellular matrix production by the adherent cells of long-term murine bone marrow cultures. Blood 61: 540-547.

56. Nair RR, Tolentino J, Hazlehurst LA (2010) The bone marrow microenvironment as a sanctuary for minimal residual disease in CML. Biochem Pharmacol 80: 602-612.

57. Bergfeld SA, Blavier L, and DeClerck YA (2014) Bone Marrow-Derived Mesenchumal Stromal Cells Promote Survival and Drug Resistance in Tumor Cells. Mol Cancer Ther.

58. Meads MB, Hazlehurst LA, and Dalton WS (2008) The Bone Marrow Microenvironment as a Tumore Sanctuary and Contributor to Drug Resistance. Clin Cancer Res 14:2519-2526.

59. Gibson LF (2002) Survival of B Lineage Leukemic Cells:Signals from the Bone Marrow Microenvironment. Leukemia \& Lymphoma 43:19-27.

60. Blobel CP (2010) 3D trumps 2D when studying endothelial cells. Blood 115: 5128-5130.

61. Grinnell F (2003) Fibroblast biology in three-dimensional collagen matrices. Trends Cell Biol 13: 264-269.

62. Santini MT, Rainaldi G, Indovina PL (2000) Apoptosis, cell adhesion and the extracellular matrix in the three-dimensional growth of multicellular tumor spheroids. Crit Rev Oncol Hematol 36: 75 87.

63. dit Faute MA, Laurent L, Ploton D, Poupon MF, Jardillier JC, et al. (2002) Distinctive alterations of invasiveness, drug resistance and cell-cell organization in 3D-cultures of MCF-7, a human breast cancer cell line, and its multidrug resistant variant. Clin Exp Metastasis 19: 161-168.

64. Kunz-Schughart LA, Freyer JP, Hofstaedter F, Ebner R (2004) The use of 3 -D cultures for highthroughput screening: the multicellular spheroid model. J Biomol Screen 9: 273-285. 